IFN Working Paper No. 926, 2012

\title{
Why Entrepreneurs Choose Risky R\&D Projects - But Still Not Risky Enough
}

Erika Färnstrand Damsgaard, Pehr-Johan Norbäck, Lars Persson and Helder Vasconcelos 


\title{
Why entrepreneurs choose risky $\mathrm{R} \& \mathrm{D}$ projects \\ - but still not risky enough*
}

\author{
Erika Färnstrand Damsgaard \\ Pehr-Johan Norbäck \\ Research Institute of Industrial Economics \\ Research Institute of Industrial Economics \\ Lars Persson \\ Research Institute of Industrial Economics and CEPR \\ Helder Vasconcelos \\ Faculdade de Economia, Universidade do Porto and CEPR
}

September 14, 2012

\begin{abstract}
Entrepreneurs face higher commercialization costs than incumbents. We show that this implies that entrepreneurs will choose more risky projects than incumbents, aiming to reduce their high expected marginal commercialization cost. However, entrepreneurs may select too safe projects from a social point of view, since they do not internalize the business stealing effect. We also show that commercialization support induces entrepreneurship but may lead to mediocre entrepreneurship by inducing entrepreneurs to choose less risky projects, whereas R\&D support encourages entrepreneurship without affecting the type of entrepreneurship. Using Swedish patent citation data, we find empirical support for predictions of the model.
\end{abstract}

\section{Introduction}

Entrepreneurs are important for economic progress as providers of "breakthrough" inventions. As Scherer and Ross (1990) point out, "new entrants without a commitment to accepted technologies have been responsible for a substantial share of the really revolutionary new industrial products and processes". Along these lines, Baumol (2004) documents that in the US small entrepreneurial firms have created a large share of breakthrough inventions whereas large established firms have provided more routinized R\&D. Further, Cohen (2010), in a review of the empirical literature on firm size and innovative activity, concludes that "[t]he key findings are

\footnotetext{
${ }^{*}$ We have greatly benefitted from comments from Richard Gilbert, Per Hjertstrand, Henrik Horn, Nicola Lacetera, Thomas Roende, Konrad Stahl, Yossi Spiegel, Jerry Thursby, and participants in seminars at IFN Stockholm, Ninth Annual Roundtable for Engineering Entrepreneurship Research 2009, Swedish Competition Authority's 3rd Workshop on Competition Research 2010, Copenhagen Business School Conference on Success in Entrepreneurship 2010, Swedish Entrepreneurship Forum Workshop for Entrepreneurship research 2010, Copenhagen Bussines School, Cagliari University, and Royal Institute of Technology (Stockholm). Financial support from Jan Wallander's Research Foundation, the Marianne and Marcus Wallenberg Foundation and from the Portuguese Ministry of Science and Technology is gratefully acknowledged. Corresponding author email: lars.persson@ifn.se.
} 
that larger, incumbent firms tend to pursue relatively more incremental and relatively more process innovation than smaller firms" 1

These observations raises some important questions. (i) Why do small independent firms (entrepreneurs) embark on radical R\&D projects characterized by great uncertainties but high value in case of success? (ii) Do the projects chosen by the entrepreneurs differ from the optimal research projects from a social point of view? These issues are addressed in this paper.

The starting point of the paper is that small independent firms have no complementary assets nor any experience when commercializing and, therefore, face much higher costs of commercializing an invention than incumbents do. As highlighted by Gans and Stern (2003, p. 333), "a key management challenge is how to translate promising technologies into a stream of economic returns for their founders, investors and employees. In other words, the main problem is not so much invention but commercialization."

We develop a model where an incumbent and an entrepreneur both invest in $R \& D$ that might lead to the creation of an invention. There are different types of $R \& D$ projects to choose among where a project with a lower probability of success has a higher payoff if it succeeds. A key feature of the model is that if the entrepreneur turns out to be successful with her chosen research project, she will face a commercialization cost. However, the incumbent is already active in the market and, therefore, will not have to pay any cost to commercialize an invention.

We first establish that the entrepreneur will choose a project with a lower probability of success than that of the incumbent. There are two effects which explain this result. Firstly, the entrepreneurship hurdle effect: The higher commercialization cost for the entrepreneur implies that the entrepreneur opts for a project that involves more risk since by so doing it reduces the expected commercialization cost (since the commersialization cost is only paid when the project succeeds). Secondly, the entry deterring effect: being successful with a minor invention the incumbent might be able to block entry by an entrepreneur. Thus, for an incumbent, a succesful innovation not only gives rise to cost savings but also entry deterrence and, therefore, the incumbent will go more safe.

How does the optimal project chosen by the entrepreneur relate to the socially optimal research project? There are two important externalities involved in the entrepreneur's choice of project. When the entrepreneur innovates, she does not internalize the expected profit stealing (the entry deterring value from the perspective of the incumbent) which hurts the incumbents. The expected profit stealing increases when projects become more certain since entry hurts rivals per se. This implies that the entrepreneur tends to choose too safe an R\&D project from a social point of view. However, there is also an expected consumer surplus gain from entry, which increases the safer the project becomes, since entry per se benefits consumers. Consequently, the social planner would, in the latter respect, prefer the entrepreneur to choose projects with less risk (thus, entering with higher probability).

We show that in a model with symmetric firms and homogeneous goods, the profit stealing

\footnotetext{
${ }^{1}$ Prusa and Schmitz (1991) provide evidence from the personal computer software industry that new firms tend to create new software categories, while established firms tend to develop improvements in existing categories. Henkel, Rønde and Wagner (2010), on the other hand, undertake a qualitative empirical study of the electronic design automation (EDA) industry, concluding that start-ups opt for R\&D projects characterized by high risk and return.
} 
effect outweighs the increase in consumers surplus. Hence, the entrepreneur tends to choose too safe a project from a social perspective. Moreover, in a model with differentiated goods, we show that this finding holds unless the products are sufficiently differentiated. If the products are sufficiently differentiated, the increase in the consumer surplus might outweigh the profit stealing effect (entry deterring effect) and, consequently, the entrepreneur will then choose too risky a project from a social perspective.

In the last few decades, entrepreneurship has emerged as a key issue on the policy arena. ${ }^{2}$ In addition, governments and policy makers have been playing a key role as facilitators of innovations by firms. An important policy debate regards the optimal design of government policies to facilitate and stimulate $\mathrm{R} \& \mathrm{D}$ and entrepreneurship. This paper will contribute to this debate by investigating the induced effects of the two following types of policies which have been used in practice: $(i)$ R\&D support and (ii) commercialization support.

First, a typical example of a pro-entrepreneurial policy is that of R\&D subsidies targeted to small and medium sized enterprises (SMEs). According to a report by the OECD (OECD (2007)), in the year 2007 several countries offered tax subsidies for R\&D targeted specifically at SMEs. Examples are: the UK, Canada, Japan, the Netherlands, Norway and Poland. In our proposed theoretical model, a tax subsidy for $\mathrm{R} \& \mathrm{D}$ reduces the $\mathrm{R} \& \mathrm{D}$ cost paid ex ante, before the outcome of the $R \& D$ project has been realized.

Second, government policy can also be geared towards supporting the commercialization of inventions that have already been developed. Examples of this type of policy are financial support for incubators, and loans specifically designed to facilitate the commercialization process in new firms. Recently, there has been a substantial increase in spending on such policies. For example, in 2009, the US Small Business Administration had approved over $\$ 13$ billion in loans and $\$ 2.7$ billion in surety guarantees to small businesses in a year. ${ }^{3}$ In our proposed model, this second type of pro-entrepreneurial policy corresponds to a decrease in the entry (commercialization) cost that an entrepreneur must pay (ex-post) in case it succeeds with its $R \& D$ project and decides to enter the market with its invention.

In this paper, we undertake a comparison of the impact of each of these policies on the type of R\&D projects that the entrepreneur as well as the incumbent will choose. We show that subsidies for $R \& D$ can induce an increase in the amount of $R \& D$, but the type of $R \& D$ project which is carried out by the entrepreneur remains unaffected. The reason is that the commercialization cost is unaffected.

As for commercialization support, we show that, following the decrease in the commercialization cost, the entrepreneur embarks on an $R \& D$ project with a higher probability of success and a lower payoff (less-breakthrough) since the entrepreneurship hurdle effect is reduced. Moreover, the incumbent's response to a decrease in the entrepreneur's commercialization cost is to also choose projects with a higher probability of success. We then show that if the profit shifting effect of entry dominates the consumer effect, both agents will choose too safe projects and the optimal policy is to subsidize R\&D but tax entry.

We also examine empirical predictions of the entrepreneurship hurdle effect: higher entry

\footnotetext{
${ }^{2}$ The Economist (14th March 2009) published a special report on entrepreneurship, "Global Heroes", describing this phenomenon.

${ }^{3}$ Source: 2009 Summary of Performance and Financial Information, US Small Business Administration, 2009.
} 


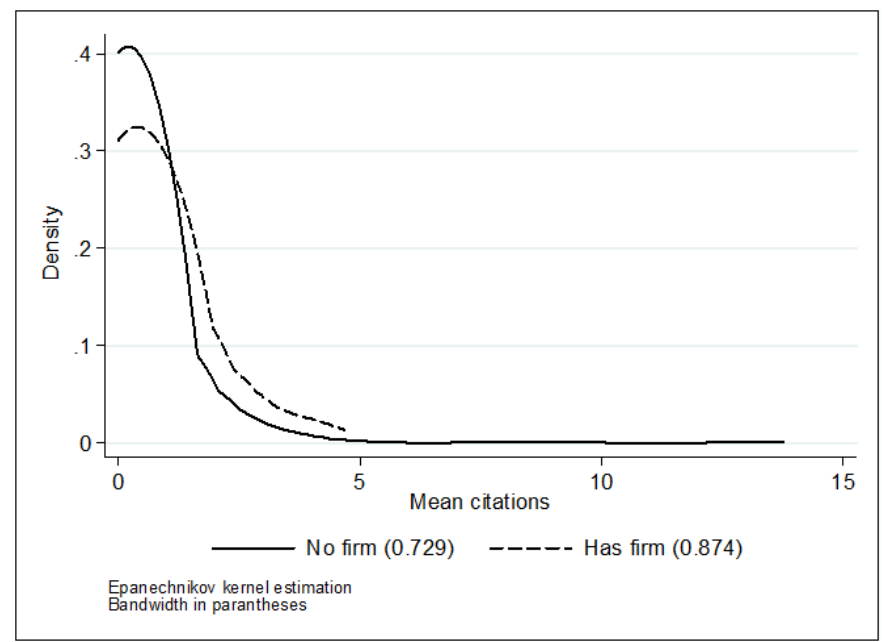

Figure 1.1: Kernel density estimation of distribution function for patent citations for patent holders who own small firm and patent holders without a firm.

costs should result in more entrepreneurial failures, since when entry barriers are high, the entrepreneur opts for an $R \& D$ project with a lower probability of success. Further, as a low success probability project is associated with a higher payoff in case of success, if the project succeeds, the invention will be "larger" or of a higher quality. Moreover, the average (expected) quality should be lower for entrepreneurs with higher entry costs, since their choices are further away from the choice maximizing the expected quality. Using detailed data on patents granted to small firms and individual inventors in Sweden, we find that the incidence of breakthrough inventions (as measured by forward patent citations) is related to the costs of commercializing the invention. ${ }^{4}$ Figure 1.1 plots the non-parametric kernel density of patent citations for the group of inventors that owned a firm at the application date (and, hence, had small commercialization costs) and the group that did not own a firm at the application date (thus facing large commercialization costs), respectively.

As illustrated by the figure, the group of inventors that face higher commercialization costs generates more failures (which we assume to be associated with zero patent citations) and more breakthrough inventions (which we assume to be associated with a high number of citations), and also on average has less citations per invention. These findings are consistent with the identified entrepreneurship hurdle effects in the theoretical analysis. We also test whether the patent citations for each group do indeed come from different distributions, using both the nonparametric Kolmogorov-Smirnov test and Levene's test of equality of variances, where both tests reject the hypothesis that the citations across the two groups have the same distribution function.

A potential concern is identifying the effect of commercialization costs on the $R \& D$ outcome of entrepreneurship i.e. the outcome of the R\&D project will affect the entrepreneur's choice of organizational form (starting a firm or being self employed). However, since our data is about firms' size at the application date when the commercial value of the invention should still be

\footnotetext{
${ }^{4}$ The data is described in more detail in Section 6 .
} 
highly uncertain, we believe this problem to be limited. Therefore, we are more concerned that our tests might suffer from omitted variable problems. In particular, there might be underlying factors for why some inventors do not want to start larger firms which might explain why they behave in a more risky way in $R \& D$. To control for this omitted variable problem, we run the Kolmogorov-Smirnov excluding inventions made at a university, inventions made by women, and inventions made by non-Swedes. Again, we can reject the hypothesis that the citations across the two groups have the same distribution function.

A limitation with our data is that $\mathrm{R} \& \mathrm{D}$ projects which do not even result in a patent are not included in our dataset. In our empirical analysis, we make the identifying assumption that a patent with zero citations is a failure. We believe that this is a reasonable assumption for many types of research projects where it is relatively easy to get a patent from the patent office but rather difficult to produce a patent that is cited. The large over-representation of zero citation patents in the data seems to support this view ${ }^{5}$.

The rest of the paper is organized as follows. In Section 2, we discuss related literature. In Section 3, we present the theoretical model and characterize the equilibrium research projects chosen by the entrepreneur and the incumbent. Section 4 establishes why entrepreneurs choose risky R\&D projects - but still not risky enough. In Section 5, we use our model to investigate the effects of pro-entrepreneurial policies on the firms' choices of research projects. In Section 6 , we examine the robustness of our main result, i.e. the entrepreneurship hurdle effect, considering scenarios which allow for commercialization by sale, several incumbent firms or several outsider entrepreneurs, and then provide empirical support for the entrepreneurship hurdle effect. Section 7 concludes the paper. Further, in the Appendix, we extend the model to allow for innovation that improves product quality or reduces the variable costs of production, and we show that in a linear Cournot model, the main mechanisms of the model still hold good.

\section{Related literature}

This paper is related to the literature on $R \& D$ and market structure. ${ }^{6}$ There are several papers studying the type of R\&D project to undertake. ${ }^{7}$ To our knowledge, however, there are only few papers considering asymmetries between firms in such a context. Cohen and Klepper (1996 a,b) examine how firm size affects the choice between process and product innovation when the returns to R\&D increase with the level of output over which the fixed costs of innovation may be spread. Rosen (1991) and Cabral (2003) determine under which conditions a leader (a larger firm) chooses the safe strategy and the follower (a small firm) chooses the risky strategy. However, they consider two incumbents with different size or different technologies, whereas we study the difference between entrepreneurs and incumbents. Henkel, Rønde and Wagner (2011) show that independent entrepreneurs which innovate for sale choose R\&D projects with a higher risk than incumbents, since incumbents have an incentive to opt for safer R\&D projects so as to improve their bargaining power in subsequent acquisitions. Haufler, Norbäck and Persson (2011) show that the limited loss offset feature of the tax system reduces the incentive for

\footnotetext{
${ }^{5} \mathrm{An}$ analogy to research in economics is that the almost all research projects lead to publications but only the successful projects leads to publications generating many citations.

${ }^{6}$ For a survey, see Gilbert (2006).

${ }^{7}$ See, for instance, Bhattachrya and Mookherjee (1986).
} 
entrepreneurs to choose risky $R \& D$ projects. We differ from these studies by focusing on the importance of the commercialization cost, the strategic interaction between the $R \& D$ choices by the entrepreneur and the incumbent, and by undertaking a welfare analysis. This enables us to show that, due to the entrepreneurship hurdle effect and the business stealing effect, entrepreneurs choose risky R\&D projects - but still not risky enough.

This paper can also be seen as a contribution to the literature on entrepreneurship (entry) and the product market (e.g. Gans and Stern (2000, 2003) and von Weizsacker (1980)). Our paper is closest in spirit to that of Mankiw and Whinston (1986) who show that if an entrant causes incumbents to reduce output in a homogenous Cournot model (i.e. the business effect is positive), entry is more desirable to the entrant than it is to society in a free entry setting, whereas there can be insufficient entry in a differentiated product model, due to a positive product variety effect of entry. Examining the probability of entry, we add to this literature by showing that entrants choose too safe projects from a social perspective if entry generates a larger profit reduction for incumbents than it increases the consumer surplus, which can be shown to hold if the products are not too differentiated. Thus, we add to this by showing that less frequent but high quality entry is preferred to more frequent and mediocre entry.

The paper is also related to the literature on financial structure and firm behavior. There, it has been shown that increased debt levels should make firms undertake more risky investments (e.g. Stiglitz and Weiss (1981)) and more risky product market decisions (Brander and Lewis (1986) and Maksimovic and Zechner (1991)). Our results concerning R\&D project type and commercialization costs are conceptually similar. Increasing the commercialization cost in our set-up (corresponding to increased debt or interest rate in that literature) implies that a larger amount of the low risk projects have negative returns which implies that the entrepreneur will put more weight on high risk projects. However, our mechanism is distinct by not relying on asymmetric information problems, but rather on the fact that the outcome of the uncertain decision is realized before some of the costs of exploiting the investment are taken. Moreover, we differ from this literature by also examining how innovation policy affects the riskiness of the $R \& D$ projects undertaken, taking into account the interaction between entrepreneurs and incumbents and undertaking a welfare analysis taking into account market power effects. This enables us to show that R\&D support can be preferred to commercialization support since it stimulates the amount of entrepreneurship but does not distort the type of entrepreneurship.

\section{The Model}

Consider a market with a unique incumbent firm. Outside this market there is an entrepreneur which can potentially enter the market. The sequence of events is shown in Figure 3.1.

In stage 1 , both firms can invest in an $R \& D$ project at a cost $R$ which, if it is successful, generates an invention. The invention can take several forms, which all increase the possessors profits: it can be a new product, a product of higher quality or a new or improved production process. To highlight our mechanism of interest, namely how commercialization costs affect the type of R\&D conducted by firms, we will use a model where the innovation reduces the fixed cost of production, denoted $\bar{F}$, which is identical for the entrepreneur and for the incumbent. In the Section A.2 in the Appendix, we generalize model to allow for innovations that improve 


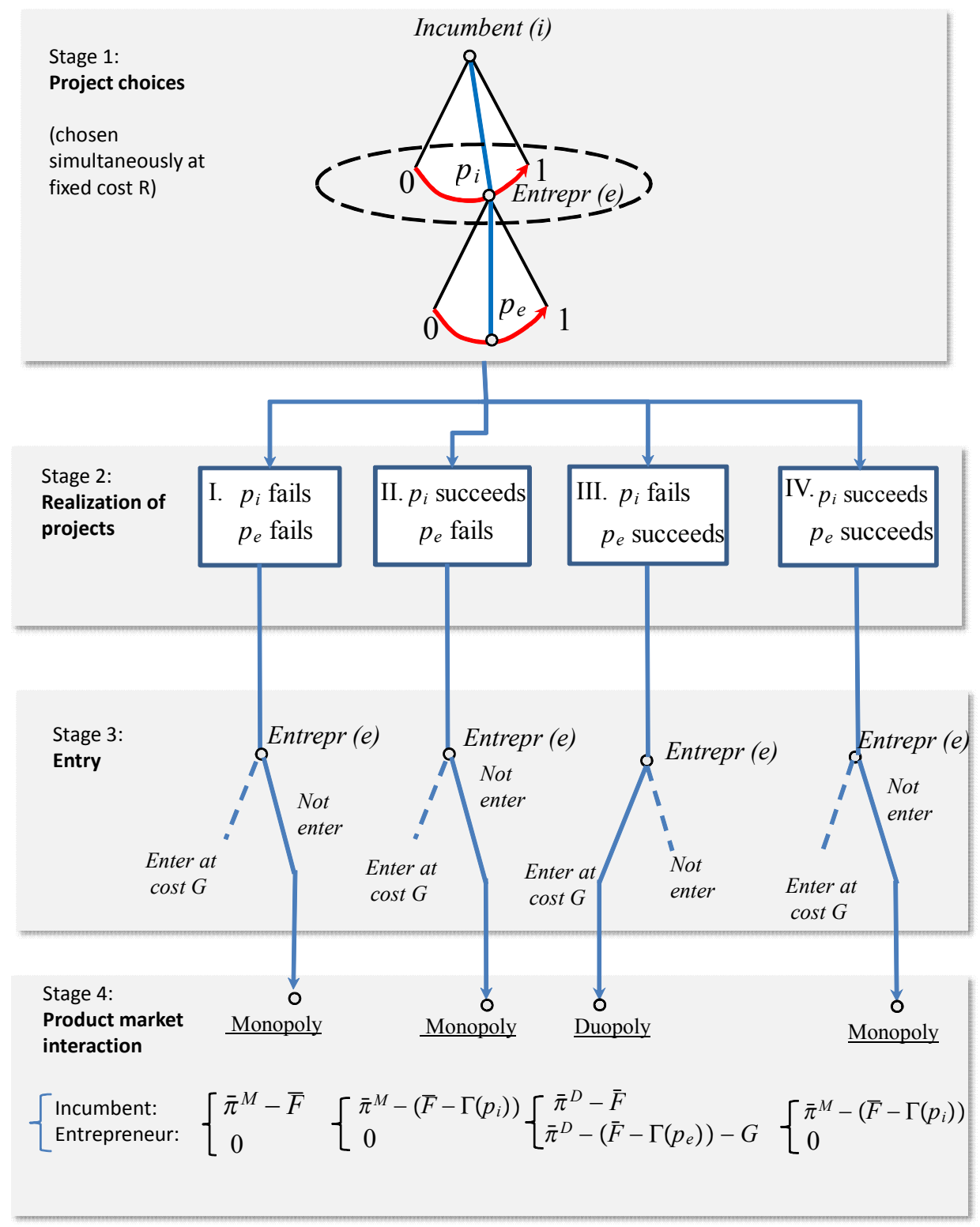

Figure 3.1: The structure of the model.

product quality or reduce the variable costs of production. ${ }^{8}$

Each agent can choose among an infinite number of independent R\&D projects. There is a cost of running a project and, to capture this, we assume that each firm can only undertake one project. ${ }^{9}$ Each project (say, project $l$ ) is characterized by a certain probability of success, denoted $p_{l}$, and a corresponding reduction in the fixed cost $\Gamma\left(p_{l}\right)$, where $\Gamma_{l}^{\prime}\left(p_{l}\right)<0, p_{l} \in(0,1)$. Along the technological frontier, the agents face a choice between projects that have a high probability of success but deliver a small reduction in fixed costs in case of success, and projects that are more risky but also have a higher associated payoff if successful. Omitting the project index, the fixed cost reduction $\Gamma(p)$ is illustrated in Figure 3.2(i). As shown in Figure 3.2(ii)

\footnotetext{
${ }^{8}$ In addition, Section A.3 adds additional entrepreneurs and incumbents and relaxes a simplifying assumption regarding the entry process.

${ }^{9}$ See Gilbert (2006) for a motivation.
} 


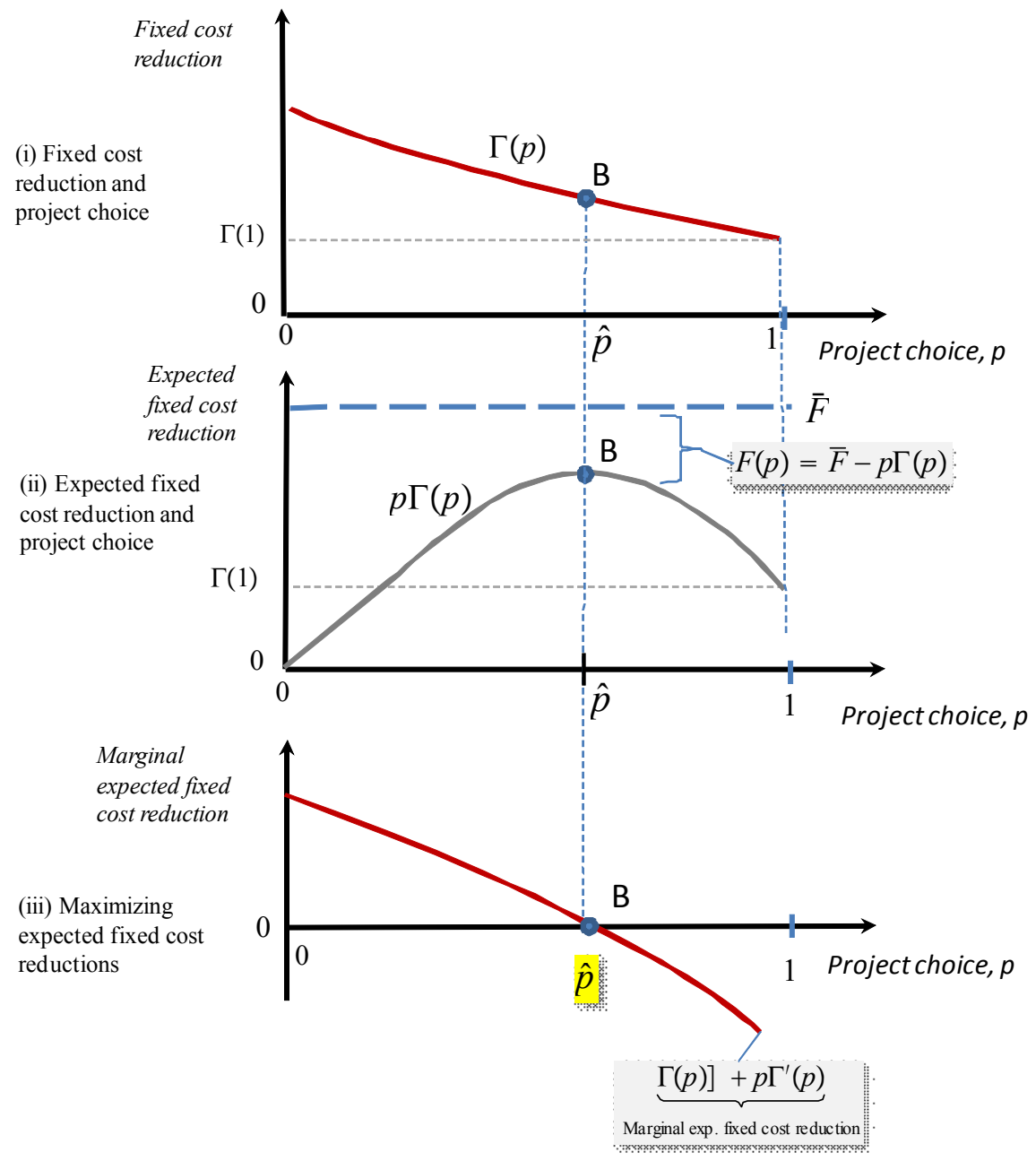

Figure 3.2: The fixed cost saving model: R\&D projects and fixed cost reduction.

and (iii), the expected fixed cost reduction $p \Gamma(p)$ is then assumed to be strictly concave in $p$ with a unique project $\hat{p}$ maximizing expected fixed cost reduction, $\hat{p}=\arg \max _{p} p \Gamma(p)$. The expected fixed production costs is the equal to $F(p)=\bar{F}-p \Gamma(p)$.

In stage 2 , the outcomes of the agents $\mathrm{R} \& \mathrm{D}$ projects $p_{j}$ are revealed. Since a project either succeeds or fails, there are two symmetric outcomes, $\left\{p_{i}\right.$ fail, $p_{e}$ fail $\}$ and $\left\{p_{i}\right.$ succeed, $p_{e}$ succeed $\}$ and two asymmetric outcomes, $\left\{p_{i}\right.$ fail, $p_{e}$ succeed $\}$ and $\left\{p_{i}\right.$ succeed, $p_{e}$ fail $\}$.

In stage 3 , given the outcome of the $R \& D$ projects, the entrepreneur makes a decision regarding whether to enter the market at a fixed commercialization cost $G$ (already sunk by the incumbent). Finally, in stage 4 , the product market interaction takes place where competition may be in quantities or in prices. The product market profit will then depend on whether the entrepreneur enters the market, on whether the firm succeeds with its selected project, and on the type of project undertaken.

In what follows, we analyze the equilibrium of the proposed game, following the usual backward induction procedure. 


\subsection{Stage 4: product market interaction}

Let $\pi_{j}\left(x_{j}, x_{-j}\right)-F_{j}$ be the product market profit of firm $j=\{i, e\}$ net of fixed costs $F_{j}=F\left(p_{j}\right)$, which result from the outcome of in stage 2 . The product market profit $\pi_{j}\left(x_{j}, x_{-j}\right)$ depends on the action taken by firm $j, x_{j}$, and the action taken by its opponent, $x_{-j}$. We then assume the existence of a unique Nash equilibrium, $\left\{x_{j}^{*}, x_{-j}^{*}\right\}$, defined from the condition:

$$
\pi_{j}\left(x_{j}^{*}, x_{-j}^{*}\right) \geq \pi_{j}\left(x_{j}, x_{-j}^{*}\right)
$$

for all $x_{j} \neq x_{j}^{*}$, which is unaffected by fixed costs $F\left(p_{j}\right)$. Since firms are symmetric, the reducedform product market profit of each firm is $\bar{\pi}^{D}=\pi_{j}\left(x_{j}^{*}, x_{-j}^{*}\right)$ under entry by the entrepreneur. If the entrepreneur does not enter and the incumbent acts a monopolist, the reduced-form product market profit is $\bar{\pi}^{M}=\pi_{i}\left(x_{i}^{M}, 0\right)$. We take the usual assumption that profits decrease in the number of firms and that consumers are better off when entry occurs, i.e. $\bar{\pi}^{M}>\bar{\pi}^{D}$ and $C S^{D}>C S^{M}$ where $C S$ denotes the consumer surplus. An example which fulfils these assumptions is the model involving quantity competition in a differentiated products market proposed by Singh and Vives (1994). This model is described in detail in the Appendix in Section A.1.

\subsection{Stage 3: Entry by the entrepreneur}

At this stage, given the outcome of the projects, the entrepreneur chooses whether or not to enter the market. We assume that in the no innovation benchmark situation, the entrant has no incentives to enter the market.

Assumption A1: When there is no innovation (or if innovation fails), the net profit from entry by the entrepreneur is negative, $\bar{\pi}^{D}-\bar{F}-G<0$, where $\bar{\pi}^{D}-\bar{F}>0$.

As illustrated in Stage 3 in Figure 3.1(iii), since $\bar{\pi}^{D}-\bar{F}-G<0$, the entrepreneur will not enter the market if its $R \& D$ project fails. In addition, the fact that $\bar{\pi}^{D}-\bar{F}>0$ implies that the incumbent will not exit market even if its $R \& D$ project fails.

As also shown in Stage 3 in Figure 3.1, we further assume that the entrepreneur can only enter when its R\&D project is successful and the incumbent's project has failed. ${ }^{10}$ This mirrors the fact that one major benefit for incumbents from innovating is that a successful innovation often serves as an entry deterring activity (see Crampes and Langinier (2002) and Gilbert and Newbery (1982)). In particular, being successful in innovating implies that the incumbent gains technical experience which makes it more likely to succeed in copying the entrepreneur's innovation, or reliably threatens to do so, and thereby reduces the likelihood of entry by the entrepreneur. Moreover, even if the entrepreneur has patented its product, high legal costs and limited access to financing may deter the entrepreneur from suing for infringement. ${ }^{11}$

\footnotetext{
${ }^{10}$ In Section A.3 we extend the analysis so as to allow the entrepreneur to enter when it succeeds with the selected R\&D project.

${ }^{11}$ We can incorporate this formally by assuming that the incumbent infringes on the entrepreneur's patent, and suing for infringement involves legal costs, $L$. Then, we can find an $L$ such that $\bar{\pi}^{D}-\left(\bar{F}-\Gamma\left(p_{e}^{*}\right)\right)-G-L<0$, whereas $\bar{\pi}^{D}-\left(\bar{F}-\Gamma\left(p_{i}^{*}\right)\right)-L>0$, since $G>0$. For expositional reasons, however, we do not pursue this here.
} 


\subsection{Stage 2: Uncertain projects revealed}

At this stage, the incumbent's and the entrepreneur's projects outcomes are revealed. Again, since each agent can succeed or fail, there are four outcomes to consider.

\subsection{Stage 1: Project choices}

We now examine the project choices of the agents. We start with the entrepreneur.

The entrepreneur's optimal R\&D project As explained above, the entrepreneur will only enter at stage 3 (upon payment of the fixed entry cost, $G$ ) if its selected R\&D project turns out to be successful in stage 2 while the incumbent's project fails. This outcome occurs with probability $p_{e}\left(1-p_{i}\right)$ and generates the net profit $\bar{\pi}^{D}-\left(\bar{F}-\Gamma\left(p_{e}\right)\right)-G$ for the entrepreneur. In addition, there is a fixed cost $R$ of conducting $\mathrm{R} \& \mathrm{D}$ which has to be paid irrespective of whether the entrepreneur succeeds or not.

The entrepreneur's expected profit is therefore given by:

$$
\mathrm{E}\left[\Pi_{e}\right]=p_{e}\left(1-p_{i}\right)\left[\bar{\pi}^{D}-\left(\bar{F}-\Gamma\left(p_{e}\right)\right)-G\right]-R .
$$

The corresponding first-order condition, $d \mathrm{E}\left[\Pi_{e}\right] / d p_{e}=0$, is

$$
\left(1-p_{i}\right)\left[\bar{\pi}^{D}-\left(\bar{F}-\Gamma\left(p_{e}^{*}\right)\right)-G\right]+\left(1-p_{i}\right) p_{e}^{*} \Gamma^{\prime}\left(p_{e}^{*}\right)=0 .
$$

The first term gives the increase in expected profit from choosing a marginally safer project. The second term, on the other hand, represents the reduction in expected profit from choosing a safer project since, if successful, the safer project will provide a smaller fixed cost reduction. It will be convenient to rewrite this first-order condition as follows:

$$
\left.\Gamma\left(p_{e}^{*}\right)\right]+p_{e}^{*} \Gamma^{\prime}\left(p_{e}^{*}\right)=\underbrace{G-\underbrace{\left(\bar{\pi}^{D}-\bar{F}\right.}_{(+)})}_{\begin{array}{c}
(+) \\
\text { Hurdle effect }
\end{array}}>0 .
$$

As illustrated in Figure 3.3, the left-hand side represents the increase in profits resulting from a lower expected fixed cost from choosing a marginally safer project. Then, turn to the righthand side. From Assumption A1, $G-\left(\bar{\pi}^{D}-\bar{F}\right)>0$. So, the entrepreneur faces a loss if entering without the invention. We label this the (entrepreneurship) hurdle effect. Note that because of the hurdle effect the entrepreneur will always choose a project which is riskier than the project $\hat{p}$ maximizing expected fixed cost reductions, i.e. $p_{e}^{*}<\hat{p}=\arg \max _{p} p \Gamma(p)$. To see why, suppose that the entrepreneur would choose $\hat{p}$. From (3.2), this cannot be optimal since by marginally reducing the probability of success from $\hat{p}$, the entrepreneur would trade off a first-order reduction of the expected net cost of commercialization, $\left(1-p_{i}\right) \hat{p}\left[G-\left(\bar{\pi}^{D}-\bar{F}\right)\right]$, against a second-order reduction of the expected fixed-cost reduction $\left(1-p_{i}\right) \hat{p} \Gamma(\hat{p})$.

Hence, by choosing a riskier project than $\hat{p}$ the entrepreneur can increase her expected profit by lowering the expected commercialization cost. As shown by Figure 3.2(ii), at an increasing 


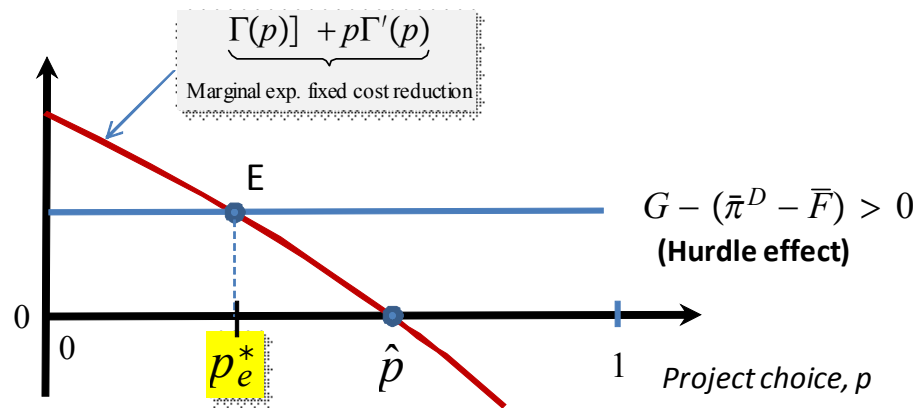

Figure 3.3: The entrepeneur's optimal project $\left(p_{e}^{*}\right)$.

distance from the cost-efficient project $\hat{p}$, the loss in profits from lower expected fixed cost reductions will increase in size. At the optimum $p_{e}^{*}<\hat{p}$ (point E in Figure 3.3), the implied loss in expected profits from a lower expected fixed cost reduction and the increase in expected profits from lower expected (net) commercialization costs then balance each other out.

What happens if the entry hurdle is increased? Differentiating (3.4) in $p_{e}$ and $G$, we obtain

$$
\frac{d p_{e}^{*}}{d G}=\frac{1}{2 \Gamma^{\prime}\left(p_{e}^{*}\right)+p_{e}^{*} \Gamma^{\prime \prime}\left(p_{e}^{*}\right)}<0
$$

where $2 \Gamma^{\prime}\left(p_{e}^{*}\right)+p_{i}^{*} \Gamma^{\prime \prime}\left(p_{e}^{*}\right)<0$ by our assumption that the expected fixed cost reduction $p \Gamma(p)$ is strictly concave in $p$. If the entry cost $G$ increases, the entrepreneur will choose a riskier project. This can be seen in Figure 3.3 by shifting the locus for the hurdle effect $G-\left(\bar{\pi}^{D}-\bar{F}\right)$ upwards and noting that $p_{e}^{*}$ must then decrease. We thus have the following proposition:

Proposition 1. If the entry cost $G$ increases, the entrepreneur chooses an $R \& D$ project with a lower probability of success and a higher payoff if successful (a "breakthrough" invention of higher quality).

To sum up, the commercialization cost is paid ex-post (in stage 3), conditional upon the success of its selected R\&D project (in stage 2). The entrepreneur therefore responds to the increase in the entry cost by choosing a project with a lower probability of success in order to reduce the expected net commercialization cost.

The incumbent's optimal R\&D project Let us now examine the choice of the incumbent. The expected incumbent's profit is

$$
\mathrm{E}\left[\Pi_{i}\right]=p_{i}\left[\bar{\pi}^{M}-\left(\bar{F}-\Gamma\left(p_{i}\right)\right)\right]+\left(1-p_{i}\right)\left\{p_{e}\left(\bar{\pi}^{D}-\bar{F}\right)+\left(1-p_{e}\right)\left(\bar{\pi}^{M}-\bar{F}\right)\right\}-R .
$$

Consider again Figure 3.1. The incumbent's R\&D project will succeed with probability $p_{i}$, in which case it earns a monopoly profit $\bar{\pi}^{M}$ and incurs a fixed production cost equal to $\bar{F}-\Gamma\left(p_{i}\right)$. Recall that, by assumption, the entrepreneur cannot enter when the incumbent succeeds. This payoff is therefore independent of $p_{e}$. With probability $\left(1-p_{i}\right)$, the incumbent's R\&D project fails. Then, if the entrepreneur's project has succeeded, the incumbent obtains a duopoly profit $\bar{\pi}^{D}$ and incurs a fixed production cost $\bar{F}$. If instead the entrepreneur's project 


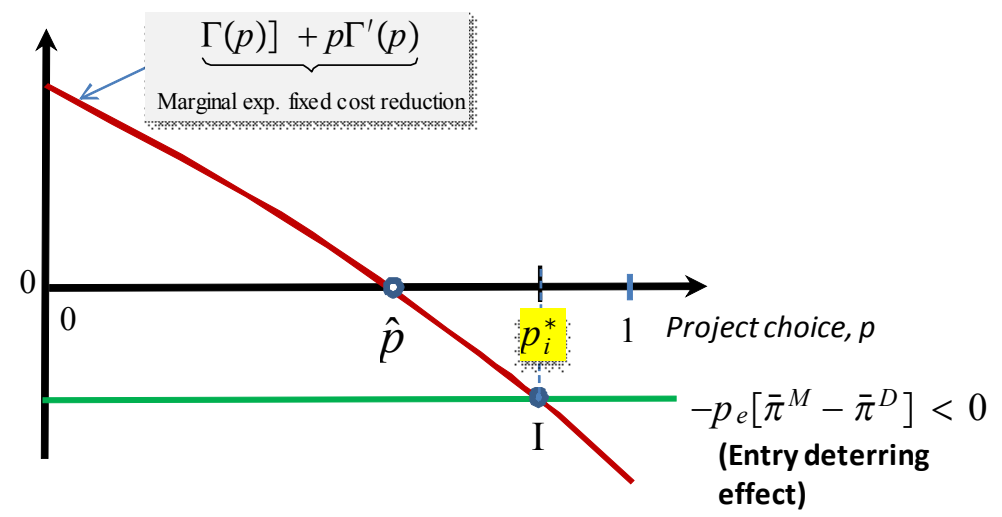

Figure 3.4: The incubent's optimal project $\left(p_{i}^{*}\right)$.

has also failed, the incumbent earns a monopoly profit $\bar{\pi}^{M}$ and still incurs a fixed production cost $\bar{F}$. In addition, the fixed cost of $\mathrm{R} \& \mathrm{D}$, paid ex-ante, is $R$.

The corresponding first-order condition, $d \mathrm{E}\left[\Pi_{i}\right] / d p_{i}=0$, is given by

$$
\bar{\pi}^{M}-\left(\bar{F}-\Gamma\left(p_{i}\right)\right)+p_{i} \Gamma \prime\left(p_{i}\right)-\left\{p_{e}\left(\bar{\pi}^{D}-\bar{F}\right)+\left(1-p_{e}\right)\left(\bar{\pi}^{M}-\bar{F}\right)\right\}=0 .
$$

The first term shows the increase in the incumbent's expected profit from choosing a safer project, where $\bar{\pi}^{M}-\left(\bar{F}-\Gamma\left(p_{i}\right)\right)$ is the net profit and $p_{i} \Gamma \prime\left(p_{i}\right)<0$ represents the decrease in the expected fixed cost reduction. As usual, the incumbent also has to consider a "replacement effect". If the incumbent fails, its expected profit is $p_{e}\left(\bar{\pi}^{D}-\bar{F}\right)+\left(1-p_{e}\right)\left(\bar{\pi}^{M}-\bar{F}\right)$ where this profit depends on whether the entrepreneur fails or not. Choosing a marginally safer project implies a higher probability of this profit being replaced, which explains the second term in (3.7).

It is once more convenient to rewrite (3.7) as follows:

$$
\Gamma\left(p_{i}^{*}\right)+p_{i}^{*} \Gamma^{\prime}\left(p_{i}^{*}\right)=-p_{e} \underbrace{\left[\bar{\pi}^{M}-\bar{\pi}^{D}\right]}_{\begin{array}{c}
(+) \\
\text { Entry Deterring }
\end{array}}<0
$$

This condition is illustrated in Figure 3.4. The left hand side is again the marginal expected fixed cost reduction. The term $\bar{\pi}^{M}-\bar{\pi}^{D}>0$ on the right hand side mirrors the fact that the monopolist will lose its monopoly position if the entrepreneur succeeds and enters the market. We denote this the entry deterring effect. Note that because of the entry deterring effect the incumbent will choose a project which is safer than the project $\hat{p}$ maximizing expected fixed cost reductions, i.e. $p_{i}^{*}>\hat{p}=\arg \max _{p} p \Gamma(p)$. To see why, suppose that the incumbent would instead choose $\hat{p}$. This cannot be optimal since by marginally increasing the probability of success from $\hat{p}$, the incumbent would trade off a first-order reduction in the expected loss from entry by the entrepreneur, $(1-\hat{p}) p_{e}\left[\bar{\pi}^{M}-\bar{\pi}^{D}\right]$, against a second-order reduction of the expected fixed-cost reduction $\left(1-p_{i}\right) \hat{p} \Gamma(\hat{p})$.

So, by choosing a marginally safer project than $\hat{p}$ the incumbent can increase its expected profit by lowering the expected loss from entry (since the entrepreneur cannot enter if the 
incumbent succeeds). But yet again, as shown by Figure 3.2(ii), at an increasing distance from the cost-efficient project $\hat{p}$, the loss in profits from lower expected fixed cost reductions will increase in size. At the optimum $p_{i}^{*}>\hat{p}$ (point I in Figure 3.4), the implied loss in expected profits from a lower expected fixed cost reduction and the increase in expected profits from lower expected loss from entry, balance each other out.

The Nash equilibrium in project choices Let us now characterize the market solution in terms of the Nash-equilibrium in project choices. From (3.4) the entrepreneur's choice of project is independent of the incumbent's choice. Thus, the reaction function of the entrepreneur is simply $\mathcal{R}_{e}=p_{e}^{*}$. This is depicted as the vertical line in Figure 3.5 (ii).

The reaction function of the incumbent $\mathcal{R}_{i}\left(p_{e}\right)$ is implicitly given by eq. (3.8). Differentiating it in $p_{e}$ and $p_{i}$, we obtain the corresponding slope $\mathcal{R}_{i}^{\prime}\left(p_{e}\right)$ :

$$
\frac{d p_{i}^{*}}{d p_{e}}=\mathcal{R}_{i}^{\prime}\left(p_{e}\right)=-\frac{\left(\bar{\pi}^{M}-\bar{\pi}^{D}\right)}{2 \Gamma^{\prime}\left(p_{i}^{*}\right)+p_{i}^{*} \Gamma^{\prime \prime}\left(p_{i}^{*}\right)}>0
$$

where once more $2 \Gamma^{\prime}\left(p_{i}^{*}\right)+p_{i}^{*} \Gamma^{\prime \prime}\left(p_{i}^{*}\right)<0$ by our assumption that $p \Gamma(p)$ is strictly concave in $p$.

We can then formulate the following proposition:

Proposition 2. For the incumbent, the two firms' probabilities of success are strategic complements: $\mathcal{R}_{i}^{\prime}\left(p_{e}\right)>0$.

The intuition for this result is already apparent from (3.8): if the entrepreneur chooses a higher probability of success, this increases the expected entry deterring effect, which induces the incumbent to choose a higher probability of success so as to avoid losing its monopoly position.

The reaction function of the incumbent $R_{i}\left(p_{e}\right)$ is depicted as the upward-sloping solid line in Figure 3.5 starting from the cost-efficient project, $\hat{p}$, which can be obtained by substituting $p_{e}=0$ into (3.8). The unique Nash-equilibrium $\left\{p_{e}^{*}, p_{i}^{*}\right\}$ is then represented by point $N$ where the reaction functions $R_{i}\left(p_{e}\right)$ and $R_{e}$ intersect. Note that the Nash-equilibrium $N$ is located to the north of the 45 degree line, implying that the entrepreneur chooses a riskier R\&D project, $p_{e}^{*}<p_{i}^{*}$.

We can then formulate the following proposition:

Proposition 3. Entrepreneurs carry out more risky innovations than in case of success: $p_{e}^{*}<p_{i}^{*}$ and, subsequently, $\Gamma\left(p_{e}^{*}\right)>\Gamma\left(p_{i}^{*}\right)$.

The proof of the previous proposition directly follows from Figures 3.3 and 3.4: Through the existence of entry costs, the hurdle effect $\left(G-\left(\bar{\pi}^{D}-\bar{F}\right)>0\right)$ induces the entrepreneur to choose a project with lower probability than the cost-efficient project $p_{e}^{*}<\hat{p}$, in order to decrease the expected net entry cost. The incumbent, on the other hand, faces no cost of entry. Instead, through the entry deterring effect $\left(-p_{e}^{*}\left[\bar{\pi}^{M}-\bar{\pi}^{D}\right]<0\right)$, it takes into account the risks of losing the monopoly profit if its $\mathrm{R} \& \mathrm{D}$ project fails and that of the entrepreneur succeeds - this induces the incumbent to choose a project with a higher probability of success than the cost-efficient project, $p_{e}^{*}>\hat{p}$. Since $p_{e}^{*}<p_{i}^{*}$, it also follows that, in case of success, 


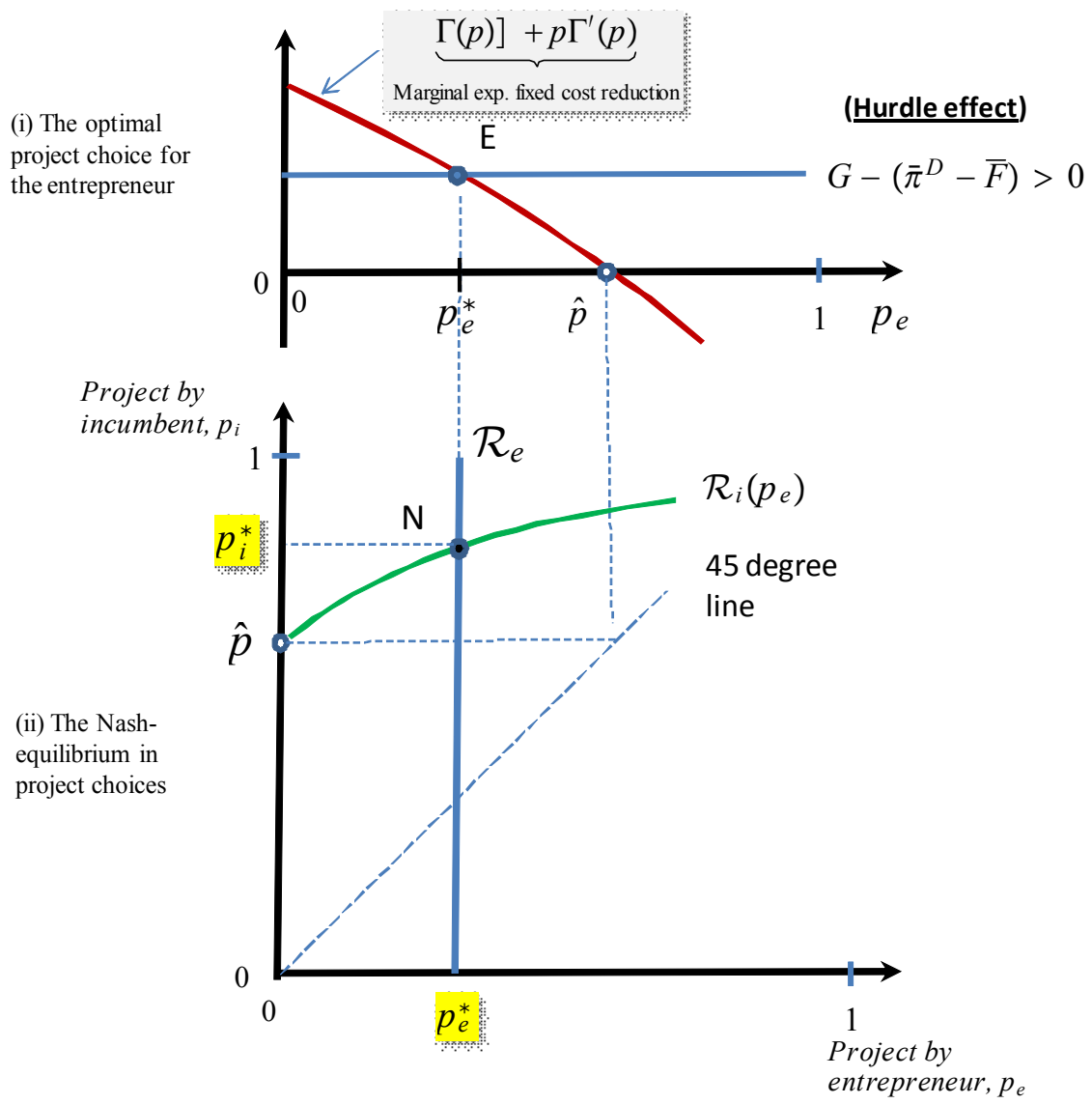

Figure 3.5: Deriving the Nash-equilibrium in project choices $(\mathrm{N})$. 
the entrepreneur's selected project contains a larger fixed cost reduction than the incumbent's selected project, $\Gamma\left(p_{e}^{*}\right)>\Gamma\left(p_{i}^{*}\right)$.

\section{Why entrepreneurs choose risky $R \& D$ projects - but still not risky enough}

Let us now compare the market solution to the first-best solution chosen by a social planner. We define welfare under the assumption of partial equilibrium and consider the expected total surplus. We can then think of the social planner in a stage 0 calculating the expected total surplus taking into account how the game evolves given the R\&D outcomes shown in Figure 3.1 .

Thus, let $\bar{W}^{M}$ be the total surplus when no firm's R\&D project succeeds, where superscript $M$ denotes monopoly. In this case, the incumbent earns net profits equal to $\bar{\pi}^{M}-\bar{F}$, consumers enjoy a surplus equal to $C S^{M}$ and total R\&D costs equal $2 R$. Let $W^{M}\left(p_{i}\right)$ be the total surplus when the incumbent succeeds with project $p_{i}$. Now, the incumbent earns net profits equal to $\bar{\pi}^{M}-\left(\bar{F}-\Gamma\left(p_{i}\right)\right)$, the consumer surplus is $C S^{M}$ and total R\&D costs equal $2 R$. Finally, let $W^{D}\left(p_{e}\right)$ be the total surplus when the entrepreneur succeeds with project $p_{e}$ and the incumbent's project fails, where superscript $D$ denotes duopoly. The entrepreneur then earns net profit $\bar{\pi}^{D}-\left(\bar{F}-\Gamma\left(p_{e}\right)\right)-G$, the incumbent earns net profit $\bar{\pi}^{D}-\bar{F}$, the consumer surplus is $C S^{D}$ and the total R\&D costs equal $2 R$. As noted in Section 3.1, increased competition in the market is assumed to increase the consumer surplus, $C S^{D}>C S^{M}$. Finally, there are positive (exogenous) externalities from research, $\xi$. To incorporate these spillovers of R\&D in a simplified way, let the spillovers from R\&D accrue across sectors in the economy and across time. Spillovers are also assumed independent of the probabilities of success. We then want to capture spillovers that the research process generates in terms of knowledge, the gains of research per se, which arise irrespective of the outcome of the particular project.

Formally, we define the total surpluses for the different outcomes as

$$
\left\{\begin{array}{l}
\bar{W}^{M}=\bar{\pi}^{M}-\bar{F}+C S^{M}-2 R+2 \xi \\
W^{M}\left(p_{i}\right)=\bar{\pi}^{M}-\left(\bar{F}-\Gamma\left(p_{i}\right)\right)+C S^{M}-2 R+2 \xi \\
W^{D}\left(p_{e}\right)=\bar{\pi}^{D}-\left(\bar{F}-\Gamma\left(p_{e}\right)\right)-G+\bar{\pi}^{D}-\bar{F}+C S^{D}-2 R+2 \xi .
\end{array}\right.
$$

First, we note that $W^{M}\left(p_{i}\right)-\bar{W}^{M}=\Gamma\left(p_{i}\right)$ : if the incumbent innovates successfully, there is no increase in the consumer surplus, the only effect is a decrease in the incumbent's fixed cost of production. Consequently, there are no positive externalities benefiting the consumers resulting from innovation by the incumbent. Second, $W^{D}\left(p_{e}\right)-\bar{W}^{M}=\left[C S^{D}-C S^{M}\right]+\bar{\pi}^{D}-$ $\bar{F}-G-\left[\bar{\pi}^{M}-\bar{\pi}^{D}\right]$ : if the entrepreneur innovates, there is an increase in the consumer surplus equal to $C S^{D}-C S^{M}$, in addition to the effects on the two firms' profits. Hence, innovation by the entrepreneur confers a positive externality on consumers, which the social planner takes into account.

The expected total surplus when both firms invest in $R \& D$ is then:

$$
E\left[W\left(p_{i}, p_{e}\right)\right]=p_{i} W^{M}\left(p_{i}\right)+\left(1-p_{i}\right)\left\{p_{e} W^{D}\left(p_{e}\right)+\left(1-p_{e}\right) \bar{W}^{M}\right\}
$$


where the first term is the total surplus if the incumbent succeeds and the second term is the total surplus if the incumbent fails. The second term is composed of two parts: $\left(1-p_{i}\right) p_{e} W^{D}\left(p_{e}\right)$ is the surplus if the entrepreneur succeeds whereas $\left(1-p_{i}\right)\left(1-p_{e}\right) \bar{W}^{M}$ is the status quo surplus when neither firm succeeds.

In what follows, we will assume that the externalities from research $\xi$ are such that the social planner prefers that both the incumbent and the entrepreneur invest in R\&D. Let $E\left[W\left(p_{i}\right)\right]=$ $p_{i} W^{M}\left(p_{i}\right)+\left(1-p_{i}\right) \bar{W}^{M}$ be the expected welfare when only the incumbent does R\&D. Then:

Assumotion A2: $E\left[W\left(p_{i}, p_{e}\right)\right]>E\left[W\left(p_{i}, 0\right)\right]$

\subsection{First-best choice for the entrepreneur}

Let us start with the first-best choice of probability of success for the entrepreneur. It is given from the first-order condition $d E\left[W\left(p_{i}, p_{e}\right)\right] / d p_{e}=0$. Using (4.2), this condition becomes

$$
W^{D}\left(p_{e}\right)+p_{e} W^{D \prime}\left(p_{e}\right)=\bar{W}^{M}
$$

where the left-hand side is the expected increase in the total surplus when the entrepreneur chooses a marginally safer project and the right-hand side is the cost in terms of replacing the status quo total surplus. Using the expressions for total surplus in (4.1), we can rewrite (4.3) as follows

$$
\Gamma\left(p_{e}^{S}\right)+p_{e}^{S} \Gamma^{\prime}\left(p_{e}^{S}\right)=\underbrace{\left[G-\left(\bar{\pi}^{D}-\bar{F}\right)\right]}_{\begin{array}{c}
(+) \\
\text { Hurdle effect }
\end{array}}+\underbrace{\left(\bar{\pi}^{M}-\bar{\pi}^{D}\right)-\left(C S^{D}-C S^{M}\right)}_{\begin{array}{c}
(?) \\
\text { Business stealing effect }
\end{array}}
$$

where $p_{e}^{S}$ is the optimal choice of probability of success from a social point of view. Comparing (3.4) and (4.4), we see that whether or not the entrepreneur chooses a too safe or a too risky project depends on the second term in (4.4), labelled the business stealing effect. The first component of this business stealing effect, $\left(\pi^{M}-\pi^{D}\right)$, is the entry deterring effect. The second component, $C S^{D}-C S^{M}$, represents the increase in the consumer surplus that occurs when the market goes from monopoly to duopoly. If the incumbent loses more from entry than what consumers gain, $\pi^{M}-\pi^{D}>C S^{D}-C S^{M}$, the business stealing effect is positive and the entrepreneur ends up choosing too safe a project from a first-best perspective, $p_{e}^{S}<p_{e}^{*}$. This case is illustrated in Figure 4.1.

Proposition 4. For any $p_{i}$, if the business stealing effect is positive, i.e if $\pi^{M}-\pi^{D}>\left(C S^{D}-C S^{M}\right)$, the entrepreneur chooses too safe projects from a social point of view: $p_{e}^{S}<p_{e}^{*}$.

If the business stealing effect is positive, the costs of entry in terms of lost profit for the incumbent outweigh the benefits to consumers and a social planner would prefer the entrepreneur to take more risk and enter the market less often. Conversely, if the business stealing effect is negative, the benefits of entrepreneurial entry outweigh the costs in terms of lost profit for the incumbent and a social planner would prefer the entrepreneur to enter the market more often, which corresponds to choosing a higher probability of success. 


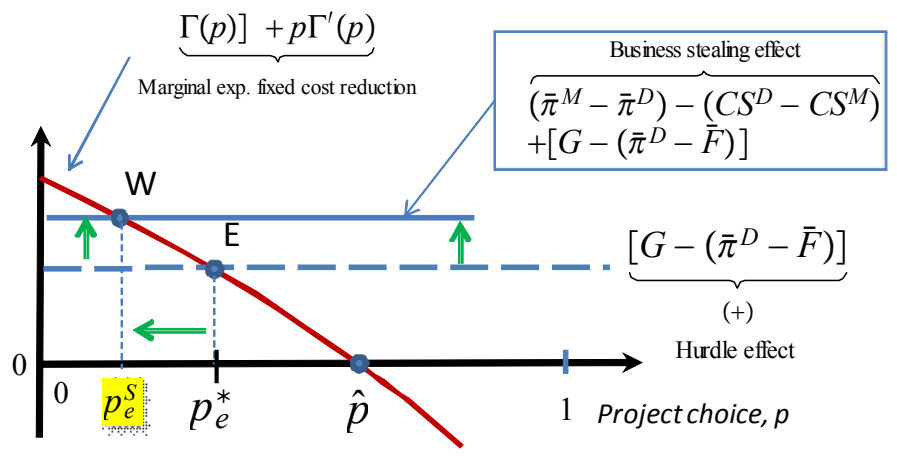

Figure 4.1: Comparing the first-best project $\left(p_{e}^{S}\right)$ and the privately optimal project $\left(p_{e}^{*}\right)$ for the entrepeneneur when the business stealing affect is positive, $\pi^{M}-\pi^{D}>C S^{D}-C S^{M}$.

\subsection{First-best for incumbent}

Let us now examine the first-best choice of the incumbent, which results from the first-order condition $d E\left[W\left(p_{i}, p_{e}\right)\right] / d p_{i}=0$. Using (4.2), this condition becomes

$$
W^{M}\left(p_{i}\right)+p_{i} W^{M \prime}\left(p_{i}\right)=p_{e} W^{D}\left(p_{e}\right)+\left(1-p_{e}\right) \bar{W}^{M}
$$

where the left-hand side is the expected increase in welfare when the incumbent chooses a marginally safer project and the right-hand side is a weighted replacement cost, where $p_{e} W^{D}\left(p_{e}\right)$ is the expected total surplus under entry and $\left(1-p_{e}\right) \bar{W}^{M}$ is the expected total surplus under status quo.

Using the expressions for total surplus in (4.1), it will be useful to write (4.5) as follows

$$
\Gamma\left(p_{i}^{S}\right)+p_{i}^{S} \Gamma^{\prime}\left(p_{i}^{S}\right)=-p_{e} \underbrace{\left(\bar{\pi}^{M}-\bar{\pi}^{D}\right)}_{\text {Entry deterring }}+p_{e}[\underbrace{\underbrace{\bar{\pi}^{D}-\left(\bar{F}-\Gamma\left(p_{e}\right)\right)-G}_{\text {Entrant's profit }}+\underbrace{C S^{D}-C S^{M}}_{\text {Consumer gain }}}_{\text {Entry effect }(+)}]
$$

In eq. (4.6), we denote the second part of the right-hand side the entry effect. It consists of the induced effect of entry by the entrepreneur on: $(i)$ the entrepreneur's profit and $(i i)$ the consumer surplus. Even though effects $(i)$ and $(i i)$ are considered by the social planner in order to determine the optimal probability of success for the incumbent, these effects are, however, not taken into account by the incumbent who only considers the first part of the right-hand side of (4.6), namely the business stealing effect.

If we examine the terms comprising the entry effect, it is clear that the first part, namely $\bar{\pi}^{D}-\left(\bar{F}-\Gamma\left(p_{e}\right)\right)-G$, is positive. If it were not, the entrepreneur would not enter the market. The second part, $C S^{D}-C S^{M}$, is also positive. Thus, comparing (3.8) to (4.6), it is clear that for the same level of $p_{e}$, it must be the case that the incumbent chooses projects with a higher probability of success than what would the social planner. We can then formulate the following proposition:

Proposition 5. For any given $p_{e}>0$, the incumbent chooses too safe projects: $p_{i}^{S}<p_{i}^{*}$

The intuition from this result is the following. There are no positive effects on consumers 
from innovation by the incumbent. On the contrary, since the entrepreneur can only enter in case the incumbent fails, innovation by the incumbent precludes entrepreneurial entry, which has a positive effect on consumers. Therefore, for a given value of $p_{e}$, such that $p_{e}>0$, the social planner prefers the incumbent to choose riskier projects which succeed less often.

It will also be useful examine the incumbent's reaction function in the first best solution. Define this optimal probability of success for the incumbent as $p_{i}^{S}=\Psi_{i}\left(p_{e}\right)$. To examine the shape of $\Psi_{i}\left(p_{e}\right)$, first note that from (4.6), $\Psi_{i}(0)=R_{i}(0)$ : the first best choice of the incumbent's project coincides with the market solution $p_{i}^{*}$ if $p_{e}=0$. Then, note that for $p_{e}>0$, Proposition 5 implies that $\Psi_{i}\left(p_{e}\right)<R_{i}\left(p_{e}\right)$ : for a given value of $p_{e}$, by ignoring the entry effect the incumbent chooses too safe a project from the social planner's point of view. Differentiating (4.6) in $p_{e}$ and $p_{i}$, we can also obtain an expression for the slope of the first-best choice

$$
\frac{d p_{i}^{S}}{d p_{e}}=\Psi_{i}^{\prime}\left(p_{e}\right)=\frac{\pi^{D}-\left(\bar{F}-\Gamma\left(p_{e}\right)\right)-G+p_{e} \Gamma^{\prime}\left(p_{e}\right)-\left\{\left(\pi^{M}-\pi^{D}\right)-\left(C S^{D}-C S^{M}\right)\right\}}{2 \Gamma^{\prime}\left(p_{i}^{*}\right)+p_{i}^{*} \Gamma^{\prime \prime}\left(p_{i}^{*}\right)} .
$$

Now, from (3.4), $\Psi_{i}^{\prime}\left(p_{e}\right)$ can be re-written making use of the the first-order condition for the entrepreneur's project

$$
\frac{d p_{i}^{S}}{d p_{e}}=\Psi_{i}^{\prime}\left(p_{e}\right)=\frac{d E[W] / d p_{e}}{\left[2 \Gamma^{\prime}\left(p_{i}^{*}\right)+p_{i}^{*} \Gamma^{\prime \prime}\left(p_{i}^{*}\right)\right]\left(1-p_{i}^{*}\right)}
$$

Then, as shown in Figure 4.2, it follows from (3.4) and (4.7) that $\Psi_{i}\left(p_{e}\right)$ is U-shaped and reaches a minimum for $\Psi_{e}=p_{e}^{S}$. The properties of the function for the social planner's optimal choice of $p_{i}^{S}$ can be summarized as follows:

Lemma 1. (i) $\Psi_{i}(0)=\mathcal{R}_{i}(0)=\hat{p}$, (ii) for $p_{e}>0, \Psi_{i}\left(p_{e}\right)<\mathcal{R}_{i}\left(p_{e}\right)$ and (iii) $\Psi_{i}\left(p_{e}\right)$ is $U$-shaped with $\Psi_{i}^{\prime}(0)<0, \Psi_{i}^{\prime}\left(p_{e}^{S}\right)=0$ and $\Psi_{i}^{\prime}\left(p_{e}\right)>0$ for $p_{e}>p_{e}^{S}$.

\subsection{When does the market provide too safe projects?}

Next, we turn to the equilibrium outcomes, comparing $\left\{p_{e}^{*}, p_{i}^{*}\right\}$ chosen by the firms to $\left\{p_{e}^{S}, p_{i}^{S}\right\}$ chosen by the social planner. Proposition 4 shows that two cases can be identified, depending on whether the business stealing effect is positive or negative.

Suppose first that the business stealing effect is positive. From Proposition 4, we have that $p_{e}^{S}<p_{e}^{*}$. Together with Proposition 5, which shows that $p_{i}^{S}<p_{i}^{*}$, we find that the market solution implies that both the entrepreneur and the incumbent choose projects with too low risk. This case is shown in Figure 4.2. The first-best solution $\left\{p_{e}^{S}, p_{i}^{S}\right\}$ is given by the intersection of the vertical line $\Psi_{e}$, which defines the social planner's optimal choice of $p_{e}^{S}$, and the U-shaped function $\Psi_{i}\left(p_{e}\right)$, which occurs at point $\mathrm{W}$ in Figure 4.2. The market solution $\left\{p_{e}^{*}, p_{i}^{*}\right\}$, on the other hand, is once more given from the intersection of the reaction functions $R_{i}\left(p_{e}\right)$ and $R_{e}$, which occurs at point $\mathrm{N}$. By construction, it must be the case that the first-best solution $\mathrm{W}$ is located south-west of the market solution $\mathrm{N}$.

We can formulate the following Corollary:

Corollary 1. If the business stealing effect is positive, $\pi^{M}-\pi^{D}-\left(C S^{D}-C S^{M}\right)>0$, the market solution provides projects with too little risk, $p_{e}^{S}<p_{e}^{*}$ and $p_{i}^{S}<p_{i}^{*}$. 


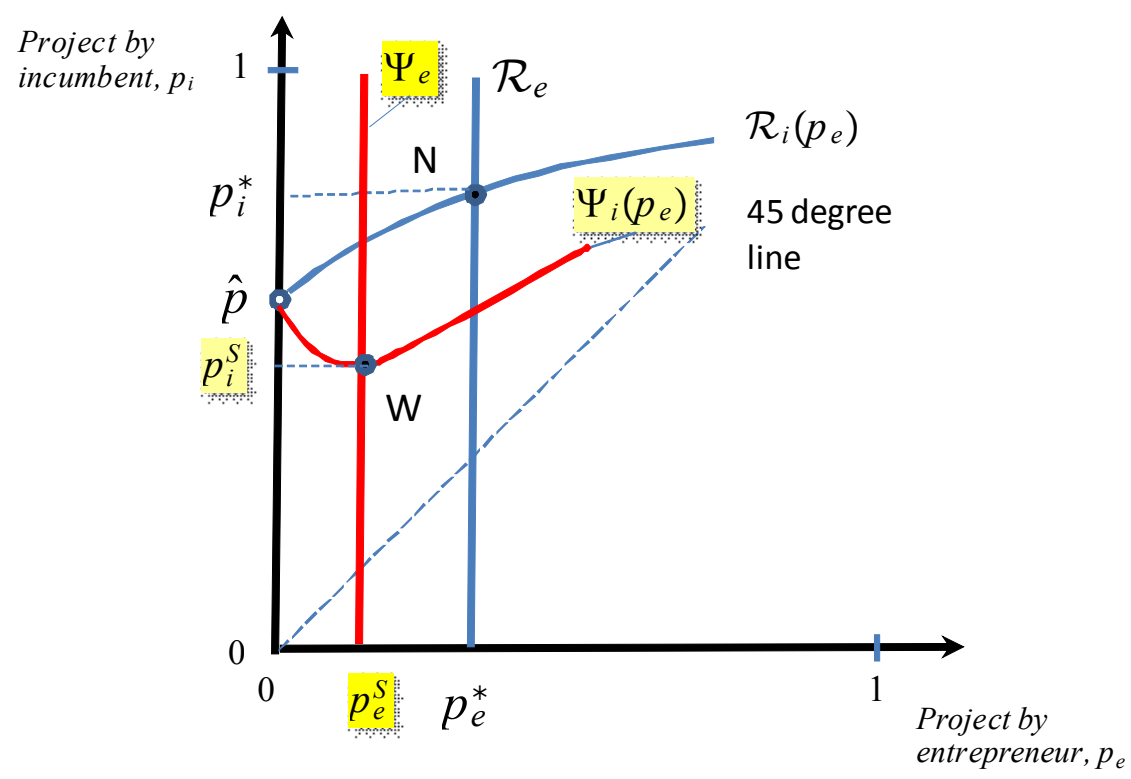

Figure 4.2: Comparing the first-best project choices (W) and Nash-equilibrium project choices (N) when the business stealing affect is positive, $\pi^{M}-\pi^{D}>C S^{D}-C S^{M}$.

If the business stealing effect is positive, the entrepreneur takes too little risk, from a social planner point of view, since it does not take into account that its entry into the market reduces the incumbent's profits. In addition, from Proposition 5, we have that the incumbent takes too little risk from a social planner point of view, since there are no benefits to consumers from innovation by the incumbent and, in addition, innovation precludes entrepreneurial entry. Hence, if the business stealing effect is positive, the market solution will provide projects with too little risk.

Suppose now that the business stealing effect is negative, such that $p_{e}^{S}>p_{e}^{*}$. Now, the market solution implies that the incumbent takes too little risk while the entrepreneur takes too much risk and the net effect is ambiguous. To explore the scenario where the market provides too little risk in more detail, we will in the following example use a linear Cournot model which can give closed form expressions for the business stealing effect. Following Singh and Vives (1984), let us assume that the utility of a consumer is given by:

$$
U\left(q_{e}, q_{i}, I\right)=a Q-\frac{1}{2}\left[q_{i}^{2}+2 \gamma q_{i} q_{e}+q_{e}^{2}\right]+I
$$

where $q_{i}$ is the output of the incumbent, $q_{e}$ is the output of the entrepreneur, $Q=q_{e}+q_{i}$ denotes total output, $I$ is a composite good of other goods and $a$ is a constant. The parameter $\gamma$ measures the substitutability between products. If $\gamma=0$, each firm has monopolistic power, whereas if $\gamma=1$, the products are perfect substitutes. Firms have identical marginal costs $c$. We then show in the Appendix that following Proposition applies:

Proposition 6. In the Singh and Vives' (1984) model of Cournot competition with differentiated goods: $(i)$ when goods are not too differentiated, i.e. if $\gamma \in\left(\frac{2}{3}, 1\right]$, the business stealing effect is positive, $\pi^{M}-\pi^{D}-\left(C S^{D}-C S^{M}\right)>0$. As a result, the entrepreneur chooses too safe a 
research project, $p_{e}^{S}<p_{e}^{*}$, as does the incumbent, $p_{i}^{S}<p_{i}^{*}$. (ii) When goods are sufficiently differentiated, i.e. if $\gamma \in\left(0, \frac{2}{3}\right)$, the business stealing effect is negative, $\pi^{M}-\pi^{D}-\left(C S^{D}-C S^{M}\right)<0$, implying that the entrepreneur chooses too risky projects, $p_{e}^{S}>p_{e}^{*}$, while the incumbent chooses projects with too little risk $p_{i}^{S}<p_{i}^{*}$.

In this example, entry will increase total output, while the incumbent will contract its output to dampen the reduction in product market price. The consumer surplus will then increase by adding consumers with decreasing willingness to pay, whereas the loss for the incumbent contracting its sales will occur at a constant price cost margin. In the homogenous goods case, this will cause the business stealing effect to be positive and, from Proposition 1, the market will provide projects with too little risk. However, when product differentiation increases, the entrepreneur steals less of the incumbent's profits upon entry and, in addition, creates a larger increase in the consumer surplus, implying that the business stealing effect is negative. Consequently, when goods are sufficiently differentiated, the business stealing effect becomes negative and the social planner prefers that the entrepreneur takes less risk. However, the incumbent still takes too little risk from a social welfare perspective.

\section{Entrepreneurial policies}

In the last few decades, entrepreneurship has emerged as a key issue in the policy arena. ${ }^{12}$ This marks a distinct break against traditional industrial policy which has focused on large established firms. An example of more pro-entrepreneurial policies is that of R\&D subsidies targeted to small and medium sized enterprises, SMEs. ${ }^{13}$ Other government policies are more geared towards supporting the commercialization of the invention. Examples of this type of policy are financial support for incubators, and loans specifically designed to facilitate the commercialization process in new firms. ${ }^{14}$ In this section, we will use our model to examine these types polices affect the agents' R\&D projects. We then turn to the policy chosen by the social planner.

Let us add a stage zero where the entrepreneur can decide to conduct R\&D or abstain from doing R\&D. From Assumption A2, the social planner wants the entrepreneur to conduct $\mathrm{R} \& \mathrm{D}$, and enter the market if it succeeds. In addition, the planner can affect the entrepreneur's decisions by subsidizing the fixed R\&D cost $R$ by an amount $r$ and/or the commercialization cost $G$ by an amount $s$. We then assume that a subsidy is a lump-sum transfer between the government and the entrepreneur. The first best solution is therefore not altered. We can then write the reduced-form expected profit for the entrepreneur as follows:

$$
E\left[\Pi_{e}\left(p_{e}^{*}, p_{i}^{*}\right)\right]=\left(1-p_{i}^{*}\right) p_{e}^{*}\left[\pi^{D}-\left(\bar{F}-\Gamma\left(p_{e}^{*}\right)\right)-(G-s)\right]-(R-r)
$$

\footnotetext{
${ }^{12}$ The Economist (14th March 2009) recently published a special report on entrepreneurship, "Global Heroes", describing this phenomenon.

${ }^{13}$ A report by OECD (2007) shows that, in the year 2007, several countries offered tax subsidies for R\&D targeted specifically at SMEs. Examples are: the UK, Canada, Japan, the Netherlands, Norway and Poland.

${ }^{14}$ Recently, there has been a substantial increase in spending on such policies. For example, in 2009, the US Small Business Administration had approved over $\$ 13$ billion in loans and $\$ 2.7$ billion in surety to small businesses in a year. (Summary of Performance and Financial Information, US Small Business Administration, 2009).
} 
In order to induce the entrepreneur to conduct R\&D and enter when successful, it must be that entry is profitable in stage 3 . Thus, the commercialization cost must fulfil:

$$
G \leq \bar{G}(s)=\pi^{D}-\left(\bar{F}-\Gamma\left(p_{e}^{*}\right)\right)+s .
$$

Furthermore, it must be profitable for the entrepreneur to take on the investment cost $R$. From (5.1) and (5.2), the R\&D cost must fulfil:

$$
R \leq \bar{R}_{E}(r, s)=p_{e}^{*}\left(1-p_{i}^{*}\right)[\underbrace{\pi^{D}-\left(\bar{F}-\Gamma\left(p_{e}^{*}\right)\right)+s}_{\bar{G}(s)}-G]+r .
$$

Let us then assume that the entrepreneurial $R \& D$ is not profitable without subsidies, while the incumbent always conducts R\&D:

Assumption A3: $R>\bar{R}_{E}(0,0)$ and $G<\bar{G}(0)$

Under Assumption A3, only the incumbent does R\&D. From (3.8), the incumbent's will then choose the cost-efficient project, $p_{i}^{*}=\mathcal{R}_{i}(0)=\hat{p}$.

$\mathbf{R} \& \mathbf{D}$ subsidies Let us first examine subsidies to $\mathrm{R} \& \mathrm{D}$. An R\&D subsidy $r$ paid before the project choice in stage 1 then implies that the entrepreneur starts to invest in $\mathrm{R} \& \mathrm{D}, R<$ $\bar{R}_{E}(r, 0)$, choosing the project $p_{e}^{*}$, given from (3.4). Since projects are strategic complements for the incumbent $\mathcal{R}_{i}^{\prime}\left(p_{e}\right)>0$ as shown in Proposition 2, this will induce the incumbent to choose a safer project, $p_{i}^{*}>\hat{p}$. From the entry-deterring effect, the incumbent can increase its expected profit when choosing a safer project as this reduces the expected loss from entry.

We have the following Lemma.

Lemma 2. Let $R>\bar{R}_{E}(0,0)$ so that only the incumbent innovates, $p_{i}^{*}=\hat{p}$. Then, when the entrepreneur has been subsidized by an amount $r$ such that $R<\bar{R}_{E}(r, 0)$, it will start undertaking $R \& D$ choosing the project $p_{e}^{*}$, and the incumbent responds to the entrepreneur's $R \& D$ investment by choosing an $R \& D$ project with a higher probability of success, $p_{i}^{*}>\hat{p}>p_{e}^{*}$

Commercialization subsidies Let us now examine subsidizing commercialization though a subsidy $s$ to the entry cost $G$ in stage 3 . As this policy implies that $R<\bar{R}_{E}(0, s)$, the same outcome is reached: the entrepreneur invests into R\&D. Proposition 1 then tells us that the entrepreneur will respond by choosing a safer project (a project with less breakthrough potential in terms of lower quality) and from Proposition 2 the incumbent will respond by also choosing a project with a lower level of risk. Thus, compared to the policy subsidizing R\&D, the commercialization subsidy will induce both the entrepreneur as well as the incumbent to choose safer projects.

Thus, we can state the following Lemma:

Lemma 3. Suppose an $R \& D$ subsidy $r$ or that a commercialization subsidy $s$ can induce the entrepreneur to invest into $R \& D, R<\bar{R}_{E}(r, 0)$ and $R<\bar{R}_{E}(0, s)$. Then, both agents will choose 
safer projects (with less potential quality if they succeed) under the subsidy to commercialization as compared to when the R\&D subsidy is used, $\left.p_{h}^{*}\right|_{r>0=s}<\left.p_{h}^{*}\right|_{s>0=r}$ for $h=\{e, i\}$.

In sum, subsidy policies can be used to induce the entrepreneur to conduct R\&D which will increase welfare from Assumption A2. However, this will also influence the project choice by the incumbent. When a policy aimed at subsidizing entry costs is used, it will affect the type of $R \& D$ project chosen by the entrepreneur which in turn affects the project that the incumbent firm chooses. We will now use these results to make some observations on optimal policy.

\subsection{When should entrepreneurial R\&D be subsidized and entry taxed}

From Proposition 4, we know that how the market outcome $\left\{p_{e}^{*}, p_{i}^{*}\right\}$ differs from the first best first-best $\left\{p_{e}^{S}, p_{i}^{S}\right\}$ will depend on the effect that entry by the entrepreneur has on consumers surplus and on the incumbent's profit, as measured by the aggregate business stealing effect, $\pi^{M}-\pi^{D}-\left(C S^{D}-C S^{M}\right)$.

Suppose that the business stealing effect is positive. As shown in the Appendix, this may arise when the incumbent's and the entrant's products are close substitutes, generating a tough product market competition. Corollary 1 then shows that the entrepreneur - as well as the incumbent - will choose too safe projects from a social point of view. The planner should then tax entry. To see this, define the axillary variable $\tilde{G}=G-s$. Then, differentiating the expected welfare and evaluating at the Nash-equilibrium $\left\{p_{e}^{*}, p_{i}^{*}\right\}$ (and making use of eqs. (3.5), (3.9), (4.4), (4.6) and (5.1)), yields:

$$
\frac{d E\left[W\left(p_{e}^{*}, p_{i}^{*}\right)\right]}{d s}=[\underbrace{\frac{\partial E\left[W\left(p_{e}^{*}, p_{i}^{*}\right)\right]}{\partial p_{e}}}_{(-)}+\underbrace{\frac{\partial E\left[W\left(p_{e}^{*}, p_{i}^{*}\right)\right]}{\partial p_{i}}}_{(-)} \underbrace{\mathcal{R}_{i}^{\prime}\left(p_{e}^{*}\right)}_{(+)}] \underbrace{\frac{d p_{e}^{*}}{d G} \frac{d \tilde{G}}{d s}}_{(-)}<0
$$

The optimal entry tax $s^{S}<0$ is then given from $\frac{d E\left[W\left(p_{e}^{*}, p_{i}^{*}\right)\right]}{d t}=0$, given $G<\bar{G}\left(s^{S}\right)$, otherwise the tax $s<0$ should be set such that $G=\bar{G}(s)$. Figure 5.1 illustrates this graphically: In Figure 5.1(i), a $\operatorname{tax}(t=-s>0)$ on entry increases the hurdle effect, inducing the entrepreneur to choose higher risk. Then, as shown in Figure 5.1(ii), the incumbent will react by choosing a more risky project as well, and the market outcome will shift from point $\mathrm{N}$ to $\tilde{\mathrm{N}}$, which is closer to the first-best solution $\mathrm{W}$ (which is unaffected by a subsidy). A subsidy to entry, on the other hand, will take the market solution further away from the first best solution; moving point $\mathrm{N}$ further to the north-east which increases the distance from the first-best solution W.

In order to have the entrepreneur conducting $\mathrm{R} \& \mathrm{D}$, the planner will complement the entry tax $s<0$ with an R\&D subsidy $r>0$ such that $R<\bar{R}_{E}(r, s)$. We can now formulate this result as follows:

Proposition 7. Suppose that Assumption $A 3$ holds and $R>\bar{R}_{E}(0,0)$. If the aggregate business stealing effect is positive $\pi^{M}-\pi^{D}-\left(C S^{D}-C S^{M}\right)>0$, the optimal policy is to subsidize $R \& D$ by the entrepreneur by an amount $r>0$ and tax entry $t=-s>0$ such that $R<\bar{R}_{E}(r, s)$.

On a final note, even if the entrepreneur would conduct $R \& D$ without a subsidy $r$, if the 


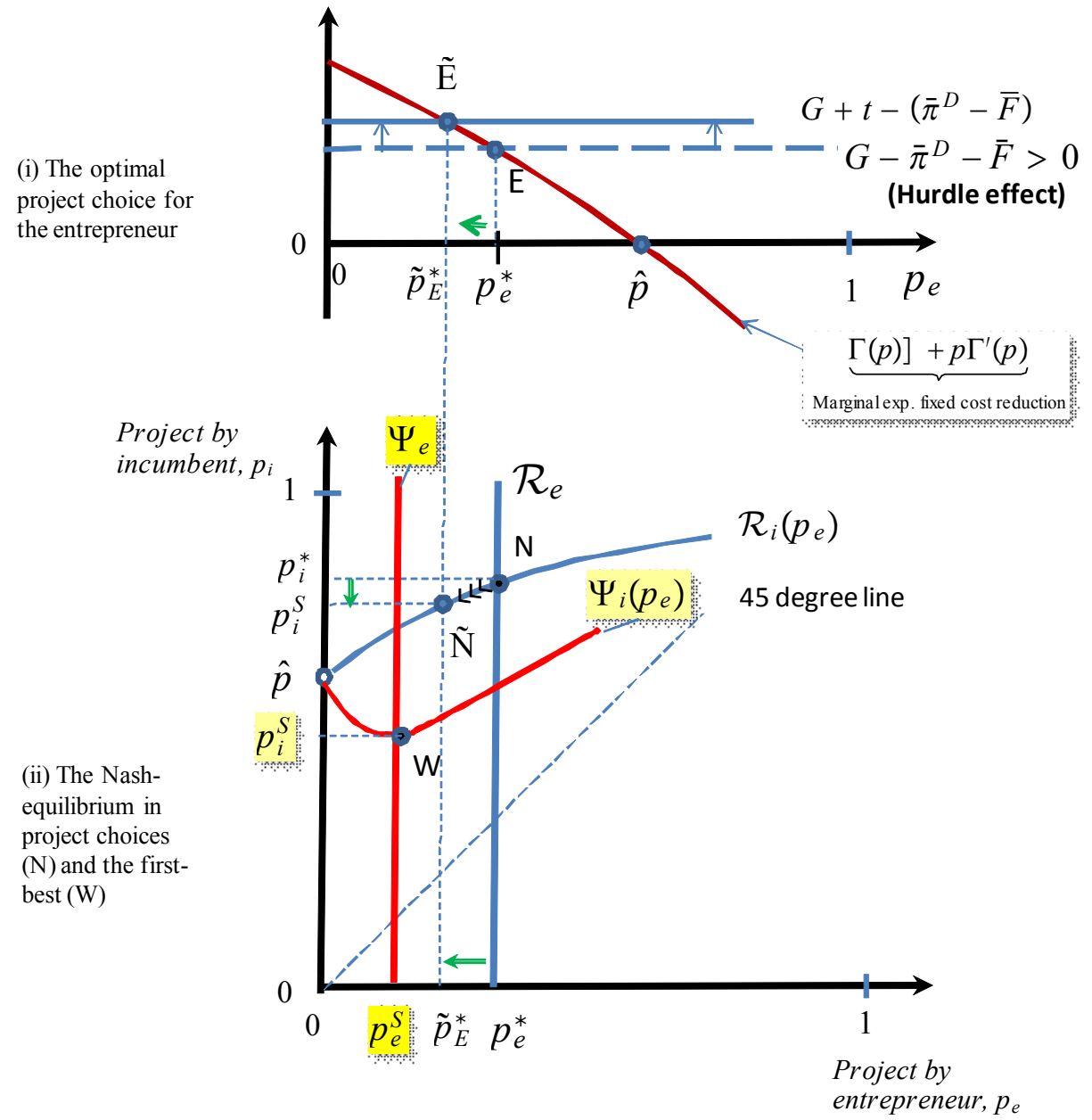

Figure 5.1: Asmall tax on entry will increase welfare when the business stealing affect is positive, $\pi^{M}-\pi^{D}>C S^{D}-C S^{M}$. 
aggregate business stealing effect is positive, the planner will always want tax entry in order to have the private incentives regarding project choices in line with social incentives.

Summing up, the social planner takes the externalities $\xi$ from research into account and, therefore, finds it optimal to subsidize the fixed cost of R\&D. However, if the business stealing effect is positive, the social planner wants the entrepreneur to conduct $R \& D$, which generates positive effects for society as a whole, but also to choose more risky projects, implying that the entrepreneur will actually enter the market less often.

\section{Empirical evidence of the hurdle effect}

The main finding in this paper is the entrepreneurship hurdle effect: Entrepreneurs choose more risky $R \& D$ projects than incumbents since they then reduce the expected net commercialization costs.

In the Appendix, we generalize this result to a model with marginal cost reductions and relax some of the assumptions made in the benchmark model. Firstly, we analyze the case when the entrepreneur can enter the market and both firms succeed. Secondly, we consider the cases where a second entrepreneur or a second incumbent exist. Finally, we also allow the entrepreneur to commercialize its invention through sale to the incumbent, instead of entering with it into the product market. By so doing, we show that it is still true that as the commercialization cost increases, the entrepreneur has more incentives to embark on $R \& D$ projects with a low probability of success and a high payoff (innovations with high quality, i.e. breakthrough innovations).

We now turn to providing empirical evidence for the entrepreneurial hurdle effect. The empirical predictions from the hurdle effect are illustrated in Figure 6.1 using, for simplicity, the benchmark fixed cost savings model.

Figure 6.1(iii) shows the effect on the optimal project choice of the entrepreneur resulting from an increase in the commercialization cost. From Proposition 1, the entrepreneur responds to an increase in the entry cost to $\tilde{G}>G$ by choosing a project with a lower probability of success, $\tilde{p}_{E}^{*}<p_{E}^{*}$, as shown by points $\mathrm{E}$ and $\tilde{\mathrm{E}}$. A lower success probability then reduces the net expected commercialization cost (the hurdle effect).

Figure 6.1(ii) then shows that the expected fixed cost reduction will decrease when the entrepreneur is induced to choose a more uncertain project: as shown by points $\mathrm{E}$ and $\tilde{\mathrm{E}}$, $\tilde{p}_{E}^{*} \Gamma\left(\tilde{p}_{E}^{*}\right)<p_{E}^{*} \Gamma\left(p_{E}^{*}\right)$. Intuitively, when faced with a stronger hurdle effect the entrepreneur's optimal project $\tilde{p}_{E}^{*}$ is now further away from the cost-efficient project, $\hat{p}=\arg \max _{p} p \Gamma(p)$.

Finally, Figure 6.1(iii) shows that - conditional on succeeding - the increase in the entry (commercialization) cost will create a larger fixed cost reduction, i.e. $\Gamma\left(\tilde{p}_{E}^{*}\right)>\Gamma\left(p_{E}^{*}\right)$. As shown by points $\mathrm{E}$ and $\tilde{\mathrm{E}}$, this follows from the fact that projects which are less likely to succeed provide larger fixed cost reduction if they do succeed, since $\Gamma^{\prime}(p)<0$.

To take the model to the data, let us think of the amount of fixed cost reductions, or the amount of marginal cost reductions, that a successful innovation brings as the quality of the innovation, $k$. For instance, in the fixed costs savings model, $k(p)=\Gamma(p)$. Assuming that $k=0$ when an innovation fails, $k^{\prime}(p)<0$ when it succeeds and that the expected quality $E[k]=p k(p)$ is strictly concave in project choice $p$, we have the following proposition: 


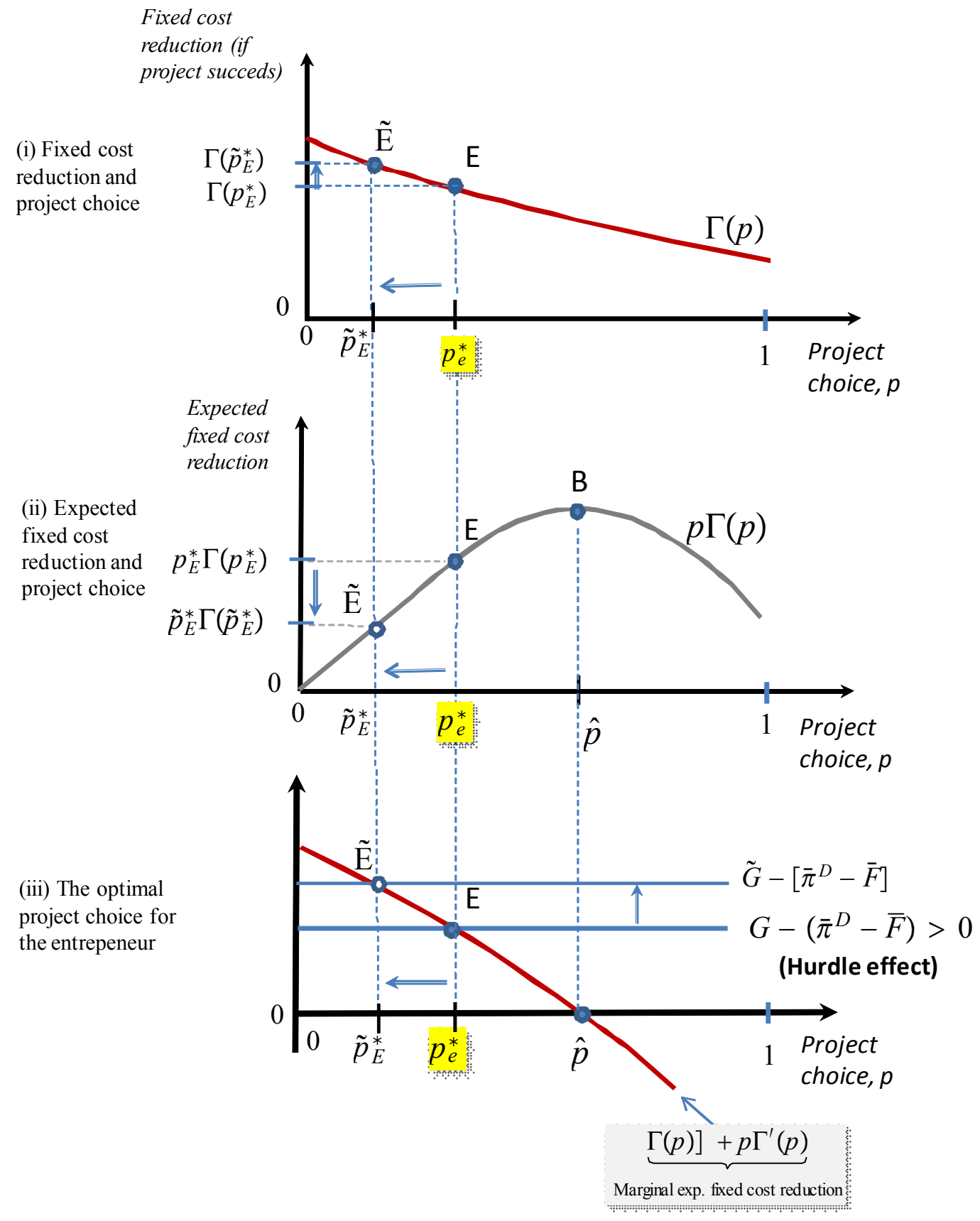

Figure 6.1: 
Proposition 8. Let the quality of an innovation be $k(p)$ with $k^{\prime}(p)<0$ and $k=0$ when an innovation fails. In addition, let $p k(p)$ be strictly concave in $p$. Suppose that Proposition 1 holds. Then, when the entry cost $G$ increases: (i) the probability of success $p_{E}^{*}$ decreases, (ii) the expected quality of the invention, $E[k]=p_{E}^{*} k\left(p_{E}^{*}\right)$, decreases and (iii) the quality given that the innovation is successful $k\left(p_{E}^{*}\right)$ increases.

\subsection{Data}

We use a dataset on patents granted to small firms and individual inventors in Sweden to analyze the distribution of invention quality. The dataset is based on a survey of Swedish patents granted in 1998. ${ }^{15}$ In that year, 1082 patents were granted to small Swedish firms (less than 200 employees) and individuals. ${ }^{16}$ Information about inventors, applying firms, their addresses and the application date for each patent was obtained from the Swedish Patent and Registration Office (PRV). Thereafter, a questionnaire was sent out to the inventors of the patents in 2004. ${ }^{17}$ The inventors were asked where the invention was created, if and when the invention had been commercialized, which kind of commercialization mode was chosen, type of financing, etc. 867 out of 1082 inventors filled out and returned the questionnaire, i.e., the response rate was 80 percent. ${ }^{18}$ We consider the 624 patents where the inventor has some ownership of the invention. 364 out of these 624 patents were commercialized, that is, the holder received income from the patent.

Entry cost, G As a proxy for the costs of entry into the product market $G$ in Proposition 8 , we use a a variable indicating whether the inventor owned a firm at the application date or not. Firms which already have marketing, manufacturing and financial resources in-house should have lower costs of entering the market for a new product. To capture the behavior of entrepreneurs, we exclude the patents which belong to firms with more than 11 employees. Of the remaining patents, 122 patents are held by inventors who are the owners or joint owners of micro companies with 2-10 employees and 405 patents are held by inventors who are selfemployed. We will then compare the group $H A S_{-}$FIRM which which consist of inventors who own or is a joint owner of a micro company. The other group NO_FIRM contains inventor that are self-employed. Note also that the hurdle effect is $G-\left(\bar{\pi}^{D}-\bar{F}\right)$. It may then be that self-employed inventors not only have higher entry costs $G$ than micro firms but also lower

\footnotetext{
${ }^{15}$ A further description of the data can be found at http://www.ifn.se/web/Databases_9.aspx and in Svensson (2007).

${ }^{16}$ In 1998, 2760 patents were granted in Sweden. 776 of these were granted to foreign firms, 902 to large Swedish firms with more than 1000 employees and 1082 to Swedish individuals and firms with less than 1000 employees.

${ }^{17}$ Each patent always has at least one inventor and often an applying firm. The inventors or the applying firm can be the owner of the patent, but the inventors can also indirectly be owners of the patent, via the applying firm.

${ }^{18}$ The non-responses were not systematic, they were due to $10 \%$ of the inventors having old addresses, $5 \%$ having correct addresses but we did not get any contact with the inventors and $5 \%$ refusing to reply. The only information we have about the non-respondents is the IPC-class of the patent and the region of the inventors. For these variables, there was no systematic difference between respondents and non-respondents.
} 
product market profits. This would would then reinforce the difference between firm types the two groups.

Quality, $k \quad$ To measure the quality of the entrepreneur's invention $k$ in Proposition 8, we use forward citations (excluding self-citations) that a patent received from the application date until November 2007. Forward citations are seen as the most important quality indicator of patents in the literature (Harhoff et al., 1999; Lanjouw and Schankerman, 1999; Hall et al., 2005). Since patents have different application years, the length of the time period they can be cited differs. Therefore, we adjust our citation variable so that it measures the number of forward citations in a five-year period. ${ }^{19}$ The 624 patents in the sample together have 636 forward citations where the cited and citing patents have at least one common technology class at the four-digit ISIC-level and 79 forward citations where they have no common technology class at the four-digit ISIC-level. We sum citations both within and across technology classes to form a variable denoted $T_{-} C I T$. We also define a dummy variable $D_{-} T_{-} C I T$ which takes on the value of one if the patent is cited, and zero otherwise.

We then use the following assumption:

Assumption A3: Patents with zero citations $T_{-} C I T=0$ identify failed R\&DD projects, i.e. innovations for which $k=0$.

We thus assume that a patent with zero citations $D_{-} T_{-} C I T=0$ is a failure. We believe that this is a reasonable approximation for many types of research projects where it is relatively easy to get a patent from the patent office but rather difficult to have patent that is cited. Consistent with this assumption, in Table 1 below, we find that more than half of the patents do not receive citations.

\subsection{Analysis}

Table 1 shows that the group $H A S_{-}$FIRM consists of the 122 patents for which the inventor owns or is a joint owner of a micro company, and the group NO FIRM consists of the 405 patents for which the inventor is self-employed.

Proposition 8(ii) implies that if the group of innovators without a firm has higher commercialization costs than the group with firms, we should observe that the latter group has a higher mean of total number of patent citations (entrepreneurs without firms choose more inefficiently risky projects to overcome the hurdle effect). Indeed, when examining the dummy variable $T_{-} T_{-} C I T$ in Panel A in table 1, we find the mean of citation for the the group that has a firm already in the market being significantly higher.

Proposition 8(i) suggests that if the group of innovators without a firm has higher commercialization costs than the group with firms, we should observe that the latter group have a lower success probability as measured by the proportion of patents being cited (entrepreneurs without firms choose more risky projects to overcome the hurdle effect). Indeed, when examining the

\footnotetext{
${ }^{19}$ Here, we follow the approach of Trajtenberg (1990) and weight the number of received patent citations by linear time trend.
} 
dummy variable $D_{-} T_{-} C I T$ in Panel B in table 1, we find that probability of being cited is almost twice as high in the group that has a firm already in the market.

We then turn to Proposition 8 (iii) which tells us that if the hurdle effect makes entrepreneurs choose more risky projects, the projects that succeed should attain higher quality. Panel $\mathrm{C}$ in Table 1 reveals that the average number of citations are also higher for no firm group, but only marginally, and the difference between the two groups is not statistically significant.

\begin{tabular}{|c|c|c|c|c|c|}
\hline & \multicolumn{5}{|c|}{ Table 1: Comparing patent citations between groups } \\
\hline Panel A. & \multicolumn{5}{|c|}{ Total number of citations: $\left(T_{-} C I T\right)$} \\
\hline Group: & $\mathrm{N}$ & Mean & Std. Dev. & t-value $(\Delta=0)$ & $\mathrm{P}$-value $(\Delta<0)$ \\
\hline$H A S_{-} F I R M$ & 122 & 0.54 & 0.07 & & \\
\hline NO FIRM & 405 & 0.35 & 0.05 & & \\
\hline$\Delta_{N O-H A S}<0$ & & -0.19 & 0.09 & -2.15 & 0.02 \\
\hline Panel B. & \multicolumn{5}{|c|}{ Dummy variable for cited $\left(D_{-} T_{-} C I T\right)$} \\
\hline Group: & $\mathrm{N}$ & Mean & Std. Dev. & $\mathrm{Z}(\Delta=0)$ & $\mathrm{P}$-value $(\Delta<0)$ \\
\hline$H A S_{-} F I R M$ & 122 & 0.52 & 0.04 & & \\
\hline NO FIRM & 405 & 0.30 & 0.02 & & \\
\hline$\Delta_{N O-H A S}<0$ & & -0.21 & 0.05 & -4.31 & 0.00 \\
\hline Panel C. & \multicolumn{5}{|c|}{ Number of citations if cited: $\left(T_{-} C I T\right.$ if $\left.D_{-} T_{-} C I T=1\right)$} \\
\hline Group: & $\mathrm{N}$ & Mean & Std. Dev. & t-value $(\Delta=0)$ & $\mathrm{P}$-value $(\Delta>0)$ \\
\hline$H A S_{-} F I R M$ & 63 & 1.24 & 0.13 & & \\
\hline NO FIRM & 123 & 1.26 & 0.14 & & \\
\hline$\Delta_{N O-H A S}>0$ & & 0.02 & 0.19 & 0.10 & 0.46 \\
\hline \multirow[t]{3}{*}{ Panel D. } & \multirow{2}{*}{\multicolumn{5}{|c|}{$\begin{array}{l}\text { Difference in the distributions of citations between the groups } \\
\text { HAS_FIRM and NO_FIRM }\end{array}$}} \\
\hline & & & & & \\
\hline & \multicolumn{2}{|l|}{ Statistic } & \multicolumn{2}{|r|}{$\mathrm{P}$-value } & \\
\hline Kolgomorov-Smirnov & \multicolumn{2}{|l|}{0.21} & \multicolumn{2}{|r|}{0.000} & \\
\hline Levene's: & \multicolumn{4}{|c|}{$\begin{array}{ll}\text { Statistic } & \text { P-value }\end{array}$} & \\
\hline $\mathrm{W}_{-} 0$ & \multicolumn{2}{|l|}{4.25} & \multicolumn{2}{|r|}{0.04} & \\
\hline $\mathrm{W}_{-} 50$ & \multicolumn{2}{|l|}{5.88} & \multicolumn{2}{|r|}{0.02} & \\
\hline $\mathrm{W}_{-} 10$ & \multicolumn{2}{|l|}{3.98} & \multicolumn{2}{|r|}{0.05} & \\
\hline
\end{tabular}

Note: The test statistic $\mathrm{W}_{-} 0$ uses mean, W_50 uses median and $\mathrm{W}_{-} 10$ uses $10 \%$ trimmed mean

The hurdle effect however also predicts that we should see more extreme outcomes when entry is more costly. To explore this in more detail, we compare the distribution function of patent citations for the group HAS_FIRM to that of the group NO FIRM. Table 2 below first gives the frequency distribution of the the citation variable $T_{-} C I T$. Indeed, we note that in the group $H A S_{-} F I R M$, there is no patent with an average of more than 5 citations per year, while in the group NOFIRM, there are two patents with an average of more than 7 citations, one of which has 13.8 citations per year. Hence, the group NO FIRM contains the patents connected to the two by far most successful inventions in this sample. 


\begin{tabular}{|c|c|c|c|c|c|c|c|c|c|}
\hline \multirow{2}{*}{ Mean citations } & \multicolumn{9}{|c|}{ Frequency of citations per patent } \\
\hline & & & & & & & & & \\
\hline Per year & 0 & $<1$ & $1-3$ & $3-5$ & $5-7$ & $7-9$ & $9-11$ & $11-14$ & total \\
\hline$H A S \_F I R M$ & $\begin{array}{c}59 \\
(48.4 \%)\end{array}$ & $\begin{array}{c}36 \\
(29.5 \%)\end{array}$ & $\begin{array}{c}20 \\
(16.4 \%)\end{array}$ & $\begin{array}{c}7 \\
(5.7 \%)\end{array}$ & 0 & 0 & 0 & 0 & 122 \\
\hline NO FIRM & $\begin{array}{c}282 \\
(69.6 \%)\end{array}$ & $\begin{array}{c}78 \\
(19.3 \%)\end{array}$ & $\begin{array}{c}38 \\
(9.4 \%)\end{array}$ & $\begin{array}{c}5 \\
(1.2 \%)\end{array}$ & 0 & $\begin{array}{c}1 \\
(0.2 \%)\end{array}$ & 0 & $\begin{array}{c}1 \\
(0.2 \%)\end{array}$ & 405 \\
\hline
\end{tabular}

Note: Percentage of total number of observations in the group is in parenthesis.

Further indication of the hurdle effect is also given in Figure 1.1. This graph plots the non-parametric kernel density of patent citations for the two groups. Note that the group $N O_{-} F I R M$ has a distribution function with more mass at zero and also more mass at high levels of citations than the group $H A S_{-} F I R M$. The same pattern emerges if we consider the inventions that have not been commercialized as failures, as depicted in Figure ??. In Panel D we also test whether the cumulative patent distribution functions (cdf) are equal for each group. We then use the non-parametric Kolmogorov-Smirnov test. The results show that we can reject the hypothesis that the citations across the two groups have the same cumulative distribution function.

If the hurdle effect induces inventors to choose projects which are more risky but also have higher potential for high quality, the variance of quality should also be higher for the group without a firm. In Panel D of Table 1, we use the Levene's test of equality of variances which is robust to non-normality. There are several variants of the test, using different formulations of the test statistic. Levene's robust test statistic uses the mean of the distribution. Brown and Forsythe (1974) proposed replacing the mean in Levene's formula with alternative location estimators. The first alternative replaces the mean with the median. The second alternative replaces the mean with the $10 \%$ trimmed mean. We report the results for all three estimators in Panel D. As seen, Levene's test rejects the hypothesis that the citations across the two groups have the same variance. In panel $\mathrm{A}$, we also apply the t-test rejects the hypothesis that the citations across the two groups have the same mean. This is basically consistent with Proposition 8(ii).

In sum, we have shown that the distribution of citations is indeed different for the group $H A S \_F I R M$ when compared to that regarding the group NO FIRM. In addition we have shown that the group $H A S_{-} F I R M$ fails significantly less often than the group the group NO FIRM. Consequently, since the group of inventors which face higher commercialization costs generates more failures (associated with zero patent citations), and also more breakthrough inventions (associated with a high number of patent citations), these results are consistent with the hurdle effect in Proposition 8.

A potential concern in identifying the effect of commercialization costs on the R\&D outcome of entrepreneurship is reverse causality, i.e. the outcome of the $\mathrm{R} \& \mathrm{D}$ project will affect the entrepreneur's choice of organization mode (firm or self employed). However, since our data is about firms' size at the application date when the commercialization value of the invention 
should still be highly uncertain, we believe this problem to be limited. Therefore, we are more concerned that our test might suffer from omitted variable problems. In particular, there might be underlying factors why some inventors do not want to start larger firms and that this might explain why they behave in a more risky way in R\&D. To control for this omitted variable problem, we ran the Kolgomorov-Smirnov test excluding inventions made at a university, inventions made by women, and inventions made by non-Swedes without qualitative change of results. In unreported regressions we also found that the difference propensity to cite patents between the two groups is significant also when controlling for industry- and regional characteristics and whether the invention made at a university, or if the innovator was a women or an immigrant.

We should finally note that many R\&D project that fail may not even result in a patent. By construction, these failures are not included in our dataset. However, the frequency distributions indicate that these failures are possibly more frequent in the group NO FIRM than in the group

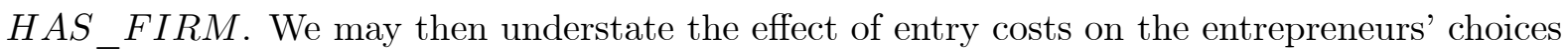
of $\mathrm{R} \& \mathrm{D}$ projects.

\section{Concluding remarks}

This paper shows that entrepreneurs have incentives to choose projects with high risk and a high potential in order to reduce expected commercialization costs. This finding is interesting in the light of the recent shift towards more pro-entrepreneurial policies all over the world as revealed in data from the World Bank Doing Business project. The cost of starting a new business declined by more than 6 percent per annum over the period 2003-08 and the decline among OECD countries has been even more dramatic. Our results suggest that this development is likely to lead to more entrepreneurial entry, but to less breakthrough inventions by entrepreneurs. In addition, incumbent firms are likely to respond to this development by (also) choosing R\&D projects with lower risk.

We also find that the social planner may prefer both incumbent firms and entrepreneurs to embark on riskier R\&D projects. Since entrepreneurial policies do not only increase entrepreneurial effort, but also affect the type of $R \& D$ projects chosen by entrepreneurs and the incumbent, this aspect should be taken into account when designing entrepreneurial R\&D policies. Consequently, our findings suggest that policies designed to reduce commercialization costs could stimulate entrepreneurship, but also stimulate entrepreneurship that takes too little risk from a social point of view.

As emphasized by Gilbert (2006), innovation diversity is a characteristic of truly independent R\&D. This paper makes an attempt to not only formally model innovation diversity, but also understand how this diversity is affected by entrepreneurial policy. We believe that this model can be used to study how different policies such as financial and educational policies affect the innovation diversity and the efficiency of the innovation market.

\section{References}

[1] Baumol, W., 2004, "Entrepreneurial Enterprises, Large Established Firms and Other Components of the Free-Market Growth Machine." Small Business Economics, Vol. 23(1), pp. 
$9-21$.

[2] Bhattacharya, S. and Mookherjee D., 1986, "Portfolio Choice in Research and Development", RAND Journal of Economics, Vol. 17, pp. 594-605.

[3] Brander, J. and Lewis, T., 1986, "Oligopoly and Financial Structure: The Limited Liability Effect", The American Economic Review, Vol. 76, No. 5, pp. 956-970

[4] Brown, M. B. and Forsythe, A. B., 1974, "Robust test for the equality of variances", Journal of the American Statistical Association, Vol. 69, pp 364-367.

[5] Cabral, L., 2003, "R\&D competition when firms choose variance", Journal of Economics $\&$ Management Strategy, Vol. 12, pp. 139-150.

[6] Cohen, Wesley M. 2010, Chapter 4 - Fifty Years of Empirical Studies of Innovative Activity and Performance, In: Bronwyn H. Hall and Nathan Rosenberg, Editor(s), Handbook of the Economics of Innovation, North-Holland, 2010, Volume 1, Pages 129-213, ISSN 2210-8807, ISBN 9780444519955, 10.1016/S0169-7218(10)01004-X.

[7] Cohen, W.M., Klepper, S. (1996a). "Firm size and the nature of innovation within industries: The case of process and product R\&D". Review of Economics and Statistics 78, $232-243$.

[8] Cohen, W.M., Klepper, S. (1996b). "A reprise of size and R\&D". Economic Journal 106, 925-951.

[9] Crampes, C., and Langinier, C., (2002), 'Litigation and Settlement in Patent Infringement Cases', RAND Journal of Economics, 33, pp. 258-274.

[10] Farrell, J. and Shapiro, C., 1990, "Asset Ownership and Market Structure in Oligopoly." RAND Journal of Economics, Vol. 21, pp. 275-292.

[11] Gans, J. S. and Stern, S., 2000, "Incumbency and R\&D Incentives: Licensing the Gale of Creative Destruction." Journal of Economics and Management Strategy, Vol. (9)4, pp. 485-511.

[12] Gans, J. S. and Stern, S., 2003, "The Product Market and the Market for 'Ideas': Commercialization Strategies for Technology Entrepreneurs." Research Policy, Vol. 32(2), pp. 333-350.

[13] Gilbert, R., 2006, "Looking for Mr. Schumpeter: Where Are We in the CompetitionInnovation Debate?", in Jaffe, A.B., Lerner, J. and Stern, S. (eds.), Innovation Policy and the Economy, Vol. 6, MIT Press, Cambridge and London, pp. 159-215.

[14] Griliches, Z., 1990, "Patent Statistics as Economic Indicators: A Survey", Journal of Economic Literature, Vol. 28(4), pp. 1661-1707.

[15] Hall, B.H., Jaffe, A.B. and Trajtenberg, M., 2005, "Market Value and Patent Citations", RAND Journal of Economics, Vol. 36(1), pp. 16-38. 
[16] Harhoff, D., Narin, F., Scherer, F.M. and Vogel, K., 1999, "Citation Frequency and the Value of Patented Inventions", Review of Economics and Statistics, Vol. 81(3), pp. 511-515.

[17] Henkel, J., Rønde, T. and Wagner; M., 2010, "And the winner is-acquired. Entrepreneurship as a contest with acquisitions as the prize", Mimeo, Copenhagen Business School.

[18] Lanjouw, J.O. and Schankerman, M., 1999, "The Quality of Ideas: Measuring Innovation with Multiple Indicators", NBER Working paper No. 7345, Cambridge, MA.6, pp. 125-156.

[19] Maksimovic, V., and J. Zechner , "Debt, Agency Costs and Industry Equilibrium", Journal of Finance, 1991, 1619-1645.

[20] Mankiw; N. Gregory and Michael D. Whinston, Free Entry and Social Inefficiency, The RAND Journal of Economics, Vol. 17, No. 1. (Spring, 1986), pp. 48-58.

[21] OECD, 1999, OECD Economic Surveys: Austria.OECD, Paris..

[22] OECD, 2002a, OECD Small and Medium Enterprise Outlook, OECD, Paris.

[23] OECD, 2002b, OECD Science, Technology and Industry Outlook, OECD, Paris.

[24] OECD, 2007, OECD Science, Technology and Industry Scoreboard, OECD, Paris.

[25] Prusa, T.J., Schmitz, J.A.Jr. (1991). "Are new firms an important source of innovation?" Economics Letters 35? 339-342.

[26] Rosen, R., 1991, "Research and Development with Asymmetric Firm Sizes.", Rand Journal of Economics, Vol. 22, pp 411-429.

[27] Scherer, F. M. and Ross, D., 1990, Industrial Market Structure and Economic Performance, Houghton Mifflin.

[28] Stiglitz, J. and Weiss, A., 1981, "Credit Rationing in Markets with Imperfect Information", The American Economic Review, Vol. 71, No. 3, pp. 393-410

[29] Svensson, R., 2007, "Commercialization of Patents and External Financing during the R\&D-Phase", Research Policy, Vol. 36(7), pp. 1052-1069.

[30] Trajtenberg, M., 1990, "A Penny for your Quotes: Patent Citations and the Value of Innovations", RAND Journal of Economics, Vol. 21(1), pp. 172-187.

[31] Von Weizsackerc,C. "A Welfare Analysis of Bamers to Entry", Bell Journal of Economics, Vol. 11 (1980),pp.399-420.

\section{A. Appendix:}

\section{A.1. The linear Cournot model with differentiated goods}

Following Singh and Vives (1984), assume the utility of a consumer to be given by:

$$
U(\mathbf{q}, I)=a Q-\frac{1}{2}\left[q_{i}^{2}+2 \gamma q_{i} q_{e}+q_{e}^{2}\right]+I
$$


where $q_{i}$ is the output of the incumbent, $q_{e}$ is the output of the entrepreneur, $Q=q_{e}+q_{i}$ denotes total output, $I$ is a composite good of other goods and $a$ is a constant. The parameter $\gamma$ measures the substitutability between products. If $\gamma=0$, each firm has monopolistic power, whereas if $\gamma=1$, the products are perfect substitutes.

Consumers maximize utility subject to the budget constraint $P_{i} q_{i}+P_{e} q_{e}+I \leq m$, where $m$ denotes income and the price of the composite good is normalized to one, $P_{I}=1$. The first-order condition for good $j$ is $\frac{\partial U}{d q_{j}}=a-q_{j}-\gamma q_{h}-P_{j}=0$ for $j \neq h$ which gives the inverse demand for firm $j$

$$
P_{j}=a-q_{j}-\gamma q_{h}, \quad j \neq h .
$$

The product market profit is given by $\pi_{j}=\left(P_{j}-c\right) q_{j}$, where $c$ is a constant marginal cost, and the first-order condition in (3.1) becomes

$$
\frac{\partial \pi_{j}}{\partial q_{j}}=P_{j}-c_{j}-q_{j}^{*}=0
$$

which can be solved for the optimal quantities $\mathbf{q}^{*}$. With symmetric firms $c_{j}=c$, defining $\Lambda=a-c$ gives:

$$
q_{i}^{M}=\frac{\Lambda}{2} \text { and } q_{i}^{D}=q_{e}^{D}=\frac{\Lambda}{2+\gamma} .
$$

Noting that $\frac{\partial \pi_{j}}{\partial q_{j}}=0$ implies $P_{j}-c_{j}=q_{j}^{*}$, the reduced-form equilibrium profits are then $\bar{\pi}_{j}^{*}=\left[q_{j}^{*}\right]^{2}$. From (A.2), prices are $P_{i}^{m}=a-q_{i}^{M}$ and $P_{i}^{D}=P_{e}^{D}=a-(1+\gamma) q^{D}$. We then have that the consumer surplus in each market structure is given by

$$
\left\{\begin{array}{l}
C S^{D}=C S\left(\mathbf{q}^{D}\right)=a Q^{D}-\frac{1}{2}\left[\left(q_{i}^{D}\right)^{2}+2 \gamma q_{i}^{D} q_{e}^{D}+\left(q_{e}^{D}\right)^{2}\right]-P_{i}^{D} q_{i}^{D}-P_{e}^{D} q_{e}^{D} \\
C S^{M}=C S\left(q_{i}^{M}\right)=a q_{i}^{M}-\frac{1}{2} q_{i}^{M}-P_{i}^{M} q_{i}^{M} .
\end{array}\right.
$$

Homogeneous goods Let us first examine entry when goods are perfect substitutes, $\gamma=1$. We have that $C S^{M}=\frac{1}{2}\left[q_{i}^{M}\right]^{2}$ and $C S^{D}=\frac{1}{2}\left[Q^{D}\right]^{2}$. In addition, some algebra shows that in this case $\bar{\pi}^{M}-\bar{\pi}^{D}-\left[C S^{D}-C S^{M}\right]=\frac{1}{24} \Lambda^{2}>0$. This gives the following Lemma:

Lemma 4. In the Linear-Cournot model with homogeneous goods, the business stealing effect is positive, $\pi^{M}-\pi^{D}-\left(C S^{D}-C S^{M}\right)>0$. As a result, the entrepreneur chooses too safe a research project, $p_{e}^{S}<p_{e}^{*}$, as does the incumbent, $p_{i}^{S}<p_{i}^{*}$.

This result is illustrated in Figure A.1. The increase in the consumer surplus from entry $\triangle C S=C S^{D}-C S^{M}$ is given as the sum of areas $\mathrm{A}, \mathrm{B}$ and $\mathrm{C}$. Entry reduces the product market price by $\Delta P=P^{M}-P^{D}$, while consumption expands with $\Delta Q=Q^{D}-q_{i}^{M}$, where $Q^{D}=q_{i}^{D}+q_{e}^{D}$. Thus, consumers face a lower price on the the "old" monopoly consumption $q_{i}^{M}$, corresponding to the rectangles $\mathrm{A}$ and $\mathrm{B}$. In addition, the consumer surplus also increases since output is higher in duopoly, corresponding to the triangle $\mathrm{C}$.

The loss in profit for the incumbent, $\Delta \pi_{i}=\bar{\pi}^{M}-\bar{\pi}^{D}$, i.e. the entry deterring effect is represented by areas A, B and D. The incumbent faces profit losses since entry by the entrepreneur reduces the incumbent's output by $\Delta q=q_{i}^{M}-q_{i}^{D}$. The total loss on these units is $\left(P_{i}^{m}-c\right) \Delta q$ 


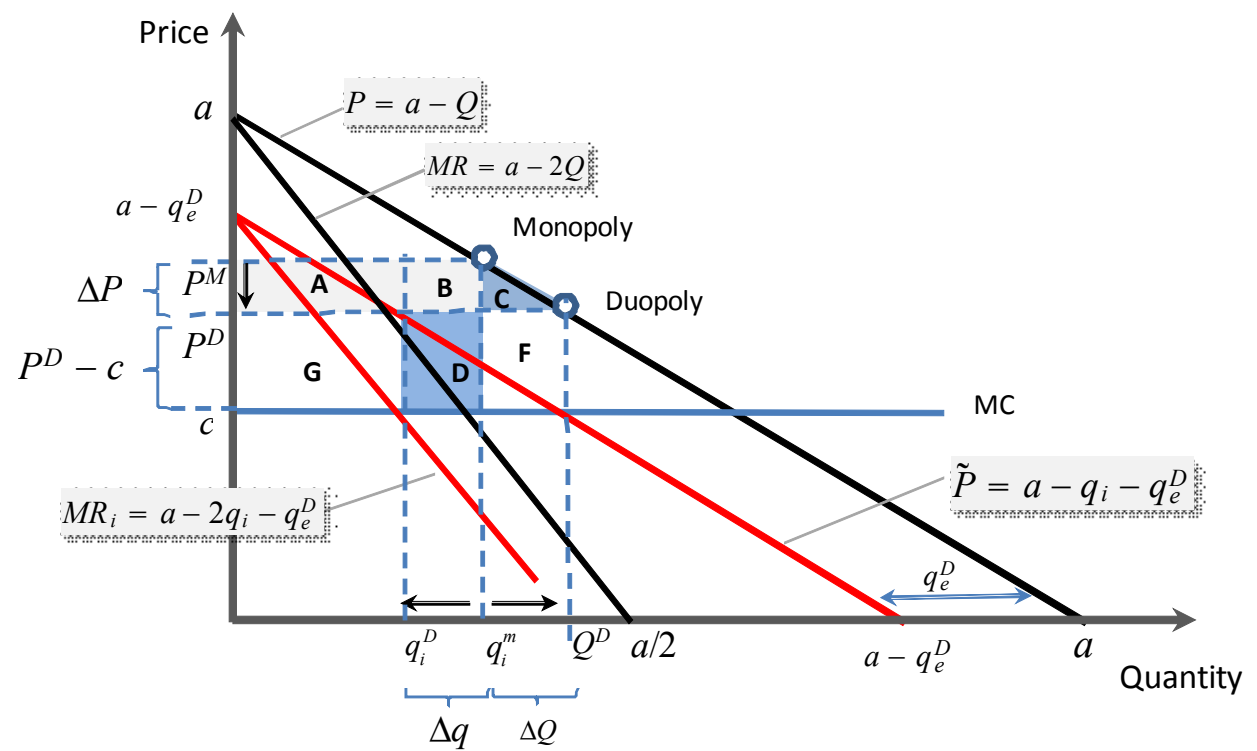

Figure A.1: The business stealing effect in a Cournot model with homogenous goods is the area D-C.

and is represented by areas $\mathrm{B}$ and $\mathrm{D}$. In addition, the monopolist faces a reduction in price on the (new) duopoly output, leading to a loss of revenues $\Delta P q_{i}^{D}$ and shown by area $\mathrm{A}$.

Areas A and B represent a transfer between the monopolist and the consumers, so the business stealing effect must be the rectangle D minus the triangle C. Note that with homogeneous goods, rectangle $\mathrm{D}$ must be larger than triangle $\mathrm{C}$. This follows from the fact that expanding consumption $\Delta Q$ adds consumers with a decreasing willingness to pay, while the loss of business from entry for the incumbent, $\Delta q$, occurs at a constant price cost margin $P^{D}-c$. Thus, with homogeneous goods and symmetric firms, the business stealing effect is always positive. From a social planner's point of view, the entrepreneur then chooses R\&D projects that are not risky enough. From Proposition 5, both firms then take on too little risk.

Differentiated goods Let us now examine entry with differentiated products, where $\gamma \in$ $(0,1)$. It is instructive to first evaluate the business stealing effect in the limiting case of $\gamma=0$, i.e. when products are independent and each firm is a monopolist, $\mathbf{q}^{M}=\left\{q_{i}^{M}, q_{e}^{M}\right\}$. Since entry does not imply any output reduction for the incumbent; $\Delta q=0, \pi_{i}\left(\mathbf{q}^{M}\right)=\pi_{i}\left(q_{i}^{M}\right)$ and $\Delta \pi_{i}=\pi_{i}\left(q_{i}^{M}\right)-\pi_{i}\left(\mathbf{q}^{M}\right)=0$. However, aggregate output increases, $\Delta Q=q_{e}^{M}>0$, because of the introduction of a new variety and, as a result, the consumer surplus must increase. To see this, note that $C S\left(q^{M}\right)=C S\left(q_{i}^{M}\right)+C S\left(q_{e}^{M}\right)$ so that $\Delta C S=C S\left(q^{M}\right)-C S\left(q_{i}^{M}\right)=C S\left(q_{e}^{M}\right)$. Thus, in the limiting case of independent products, the business stealing effect is negative, $\Delta \pi_{i}-\Delta C S=-C S\left(q_{e}^{M}\right)<0$.

Since we have shown that the business stealing effect is positive for the case of homogenous products $(\gamma=1)$ and negative for the case of independent products $(\gamma=0)$, then, by continuity, there must exist a cut-off differentiation such that the business stealing effect turns negative. To see this, first note that the consumer surplus under monopoly is $C S^{M}=\frac{1}{8} \Lambda^{2}$, and under duopoly it is $C S^{D}=\Lambda^{2} \frac{\gamma+1}{(\gamma+2)^{2}}$. Note that $\frac{\partial C S^{D}}{\partial \gamma}<0$, which implies that the consumer surplus 
in a duopoly market is increasing in product differentiation. Then, some algebra shows that

$$
\pi^{M}-\pi^{D}-\left(C S^{D}-C S^{M}\right)=\frac{1}{8} \Lambda^{2} \frac{3 \gamma-2}{\gamma+2} .
$$

From (A.6), we can solve for the level of $\tilde{\gamma}$ such that $\left(\pi^{M}-\pi^{D}\right)-\left(C S^{D}-C S^{M}\right)=0$. Then, we can formulate the following Lemma:

Lemma 5. In the Linear-Cournot model when goods are sufficiently differentiated, i.e. if $\gamma \in$ $\left(0, \frac{2}{3}\right)$, the business stealing effect is negative, $\pi^{M}-\pi^{D}-\left(C S^{D}-C S^{M}\right)<0$, implying that the entrepreneur chooses too risky projects: $p_{e}^{S}>p_{e}^{*}$, while the incumbent chooses projects with to little risk $p_{i}^{S}<p_{i}^{*}$.

If the parameter that determines product differentiation, $\gamma$, is sufficiently low so that $\gamma \in\left[0, \frac{2}{3}\right)$, the business stealing effect is negative. Consequently, if goods are sufficiently differentiated, the social planner prefers that the entrepreneur takes less risk. This is explained by the fact that as product differentiation increases, the entrepreneur steals less of the incumbent's profits upon entry and, in addition, creates a larger increase in the consumer surplus. Once more, since the incumbent does not internalize the entry effects in terms of the entrepreneur's profit, on the one hand, and on the consumer surplus, on the other, it ends up embarking on projects with too little risk from a social welfare perspective.

\section{A.2. Generalization}

Let us now use a more general formulation of $R \& D$ projects, where an invention can take several forms, which all increase the firm profits: it can be a new product, a product of higher quality or a new or improved production process. As before, each project is characterized by a probability of success $p_{l} \in(0,1)$. Let $k_{l}=k\left(p_{l}\right)$ denote the corresponding project quality, where a higher quality increases the pay-off associated with a successful invention $\frac{d \pi}{d k_{l}}>0$ but project quality and probability of success are inversely related, $\frac{d k}{d p_{l}}<0$. Hence, a project with a lower probability of success is then associated with a higher quality and a higher payoff, whereas a project with a higher probability of success is associated with a lower quality and a lower payoff. That is, the more profitable is an invention, the more difficult it is to develop, $\frac{d \pi\left(p_{l}\right)}{d p_{l}}=\frac{d \pi}{d k} \frac{d k}{d p_{l}}<0$. We define a reduced-form pay-off function as $\pi\left(p_{l}\right) \equiv \pi\left(k\left(p_{l}\right)\right)$. In addition, in order to have a well-behaved model, we will assume that the profit function has the following properties:

Assumption A2: Monopoly profits. (i) $\pi\left(p_{l}\right) \in(\bar{\pi}, \infty)$, (ii) $\pi^{\prime}\left(p_{l}\right)<0$ and $\pi^{\prime}\left(p_{l}\right)>-\infty$, and (iii) $\frac{d^{2}\left(p_{l} \pi\left(p_{l}\right)\right)}{d p_{l}^{2}}=2 \pi^{\prime}\left(p_{l}\right)+p_{l} \pi^{\prime \prime}\left(p_{l}\right)<0$

Assumption A2(i) states that a successful project always gives a higher profit than the incumbent's status-quo profit, while the profit is bounded from infinity. Assumption A2(ii) states that a project with a higher probability of success has a corresponding lower profit. Finally, Assumption A2(iii) states that the expected pay-off function $p_{l} \pi\left(p_{l}\right)$ is strictly concave, implying that $p_{l}^{*}=\arg \max _{p_{l}} p_{l} \pi\left(p_{l}\right) \in(0,1)$. 
We define the duopoly profits as follows: $\pi_{i}^{D}\left(p_{e}\right)$ is the incumbent's duopoly profit, and $\pi_{e}^{D}\left(p_{e}\right)$ is the entrepreneur's duopoly profit, where the superscript $D$ denotes duopoly. Note that the duopoly profits are independent of $p_{i}$, since the duopoly competition occurs only if the incumbent's R\&D project has failed. Moreover, we make the following assumption about duopoly profits:

Assumption A3: Duopoly profits. (i) $\pi_{i}^{D}\left(p_{e}\right) \in(0, \bar{\pi})$, (ii) $\frac{d \pi_{i}^{D}\left(p_{e}\right)}{d p_{e}}=\pi_{i}^{D^{\prime}}\left(p_{e}\right) \in(0, \infty)$, and (iii) $\frac{d^{2}\left(p_{e} \pi_{e}^{D}\left(p_{e}\right)\right)}{d p_{e}^{2}}=2 \pi_{e}^{D \prime}\left(p_{e}\right)+p_{e} \pi_{e}^{D^{\prime \prime}}\left(p_{e}\right)<0$.

Assumption A3(i) states that the incumbent's profit is reduced by entry, but it is positive. Assumption A3(ii) states that the incumbent's profit increases when the entrepreneur chooses a project that is more likely to succeed (since the associated quality is lower). Finally, Assumption A3(iii) states that the expected duopoly profit for the entrepreneur is strictly concave.

In what follows, we characterize the firm's optimal behavior in this extended setting.

\section{A.2.1. The entrepreneur's optimal R\&D project}

The entrepreneur's expected payoff is given by:

$$
\mathrm{E}\left[\Pi_{e}\right]=p_{e}\left(1-p_{i}\right)\left[\pi_{e}^{D}\left(p_{e}\right)-G\right]-R
$$

which is identical to (3.2), apart from the formulation of profits from a successful invention. The first-order condition, $d \mathrm{E}\left[\Pi_{e}\right] / d p_{e}=0$, is then:

$$
\pi_{e}^{D}\left(p_{e}^{*}\right)+p_{e}^{*} \pi_{e}^{D \prime}\left(p_{e}^{*}\right)=G
$$

which differs from (3.4) only by the constant terms $\bar{\pi}^{D}$ and $\bar{F}$.

Differentiating (A.8) in $p_{e}$ and $G$, we obtain $\frac{d p_{e}^{*}}{d G}<0$ just as in the benchmark model with fixed cost innovation.

\section{A.2.2. The incumbent's optimal $R \& D$ project}

Turning to the incumbent, we have that the incumbent's expected payoff is given by:

$$
\mathrm{E}\left[\Pi_{i}\right]=p_{i} \pi\left(p_{i}\right)+\left(1-p_{i}\right)\left[p_{e} \pi_{i}^{D}\left(p_{e}\right)\left(1-p_{e}\right) \bar{\pi}\right]-R
$$

which is once more identical to (3.6), apart from the formulation of profits from a successful invention. The corresponding first-order condition, $d E\left[\Pi_{i}\right] / d p_{i}=0$, is

$$
\pi\left(p_{i}^{*}\right)+p_{i}^{*} \pi^{\prime}\left(p_{i}^{*}\right)=\bar{\pi}-p_{e}\left[\bar{\pi}-\pi_{i}^{D}\left(p_{e}\right)\right] .
$$

Compared to the expression in (3.8), the term on the r.h.s now contains two terms: $(i)$ the loss of the status quo profit $\bar{\pi}$ which we denote the monopoly replacement effect; and (ii) the duopoly profit (when the entrepreneur succeeds and the incumbent fails) $\pi_{i}^{D}\left(p_{e}\right)$, which we denote the duopoly replacement effect, where the first effect is absent in the fixed cost model, since the incumbent's invention only affects the fixed cost of production and not the good sold. 
In the main model, Proposition 3 shows that $p_{e}^{*}<p_{i}^{*}$. In this case, comparing the first-order condition for the entrepreneur and that of the incumbent, (A.8) and (A.9), we note that the left-hand side of the expressions is strictly decreasing in $p_{l}, l \in\{e, i\}$. Turning to the right-hand sides, we cannot determine whether $p_{e}^{*}<p_{i}^{*}$ or not. The intuition is that the incumbent now takes into account that by innovating, he will to some extent replace his own profits, which may make him choose a project with a higher risk than that of the entrepreneur. However, we have that $\lim _{F \rightarrow \pi_{e}^{D}(0)} p_{e}^{*}(G)=0$. When the entry cost for the entrepreneur $G$ approaches $\pi_{e}^{D}(0)$, the project chosen by the entrepreneur approaches $p_{e}^{*}=0$. In the limit, the incumbent acts as a monopolist, choosing the success probability $p_{i}^{M}>0$. Consequently, we can show that when $F \rightarrow \pi_{e}^{D}(0)$, then $p_{i}^{*}>p_{e}^{*}$.

The entrepreneur's reaction function $\mathcal{R}_{e}=p_{e}^{*}$ is then given from equation (A.8), while equation (3.8) implicitly defines the incumbent's reaction function $\mathcal{R}_{i}\left(p_{e}\right)$, whose slope is given by:

$$
\mathcal{R}_{i}^{\prime}\left(p_{e}\right)=-\frac{\bar{\pi}-\pi_{i}^{D}\left(p_{e}\right)-p_{e} \pi_{i}^{D^{\prime}}\left(p_{e}\right)}{2 \pi^{\prime}\left(p_{i}^{*}\right)+p_{i}^{*} \pi^{\prime \prime}\left(p_{i}^{*}\right)}
$$

and comparing it to (3.9), we see that the sign of the reaction function is now ambiguous.

Turning to the analysis of socially optimal project choices, expected welfare is

$$
E[W]=p_{i} W\left(p_{i}\right)+\left(1-p_{i}\right)\left[p_{e} W^{D}\left(p_{e}\right)+\left(1-p_{e}\right) \bar{W}\right]
$$

where $\bar{W}=\bar{C} S+\bar{\pi}-2 R+2 \xi, W\left(p_{i}\right)=C S\left(p_{i}\right)+\pi\left(p_{i}\right)-2 R+2 \xi$ and $W^{D}\left(p_{e}\right)=C S^{D}\left(p_{e}\right)+$ $\pi_{e}^{D}\left(p_{e}\right)-G+\pi_{i}^{D}\left(p_{e}\right)-2 R+2 \xi$. The first-order condition $d E[W] / d p_{i}=0$ then determines the incumbent's first best project choice $p_{i}^{S}=\Psi_{i}\left(p_{e}\right)$ and, $d E[W] / d p_{e}=0$, determines the entrepreneur's first-best project choice $p_{e}^{S}$.

In order to show the coherence between the model with fixed cost innovation and this more general one, we use the linear Cournot model with homogenous goods, i.e. let $\gamma=1$ in eq. (A.1). Then, assume that a successful invention leads to a reduction in the marginal cost level. Making a distinction between firm types, we then have:

$$
c_{i}^{\text {Nosucc }}=c, \quad c_{i}^{\text {Succ }}=c-\left(1-p_{i}\right), \quad c_{e}^{\text {Succ }}=c-\left(1-p_{e}\right)
$$

where we once more note the trade-off faced by firms: choosing a safer project reduces the marginal cost less. Reduced-form profits are once more quadratic in output, $\pi_{j}=\left[q_{j}^{*}\right]^{2}$ and the optimal quantities are given by $\bar{q}=\frac{\Lambda}{2}, q_{i}^{*}\left(p_{i}\right)=\frac{\Lambda+1-p_{i}}{2}, q_{i}^{D}\left(p_{e}\right)=\frac{\Lambda-\left(1-p_{e}\right)}{3}$, and $q_{e}^{D}\left(p_{e}\right)=$ $\frac{\Lambda+2\left(1-p_{e}\right)}{3}$, where $\Lambda=a-c>1$. Inserting these profits into (A.8) and (A.10), we obtain

$$
p_{e}^{*}(\Lambda, G)=\frac{\Lambda+2}{3}-\frac{\sqrt{\Lambda^{2}+4 \Lambda+27 G+4}}{6}, p_{i}^{*}(\Lambda, G)=\frac{2 \Lambda+2}{3}-\frac{\sqrt{\Lambda^{2}+2 \Lambda+12 \Phi(\Lambda, G)+1} 1}{3}
$$

where $\Phi(\Lambda, G)=p_{e}^{*}(\Lambda, G)\left(\frac{\Lambda-\left(1-p_{e}^{*}(\Lambda, G)\right)}{3}\right)^{2}+\left(1-p_{e}^{*}(\Lambda, G)\right)\left(\frac{\Lambda}{2}\right)^{2}$.

We can then derive the following results:

Lemma 6. In the Cournot model described with homogenous goods, (i) $p_{e}^{*}<p_{i}^{*}$, (ii) if $\Lambda=$ $a-c>8 / 5, \mathcal{R}_{i}^{\prime}\left(p_{e}\right)>0$, (iii) if $\Lambda=a-c \geq 2, p_{e}^{S}<p_{e}^{*}$. 


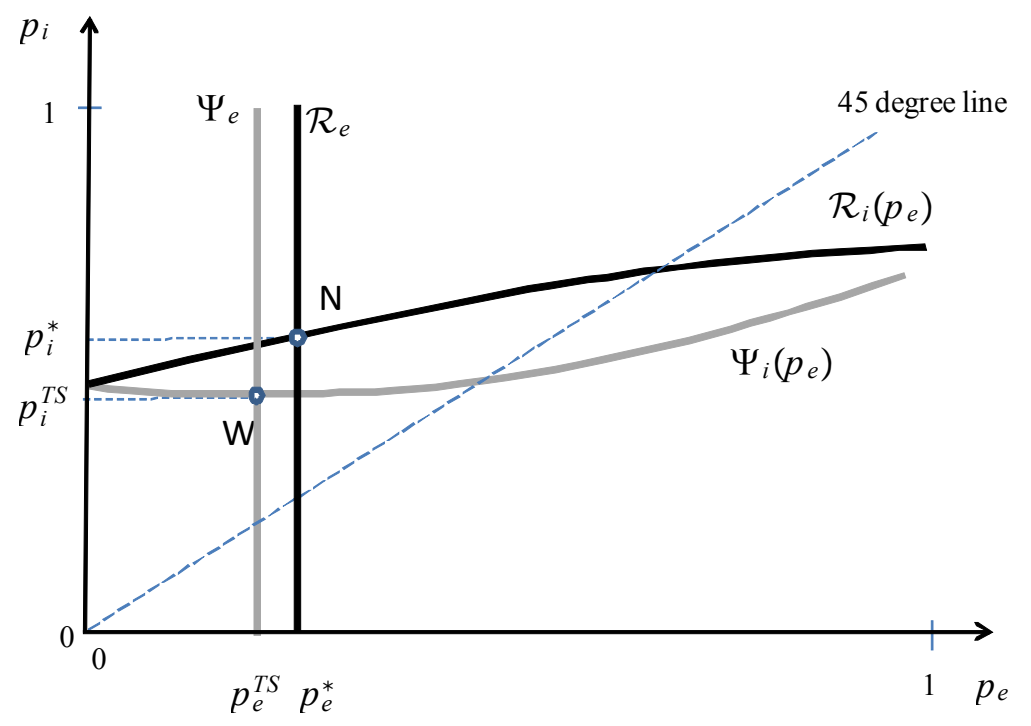

Figure A.2: The variable cost saving model. The Nash equilibrium is given in point $\mathrm{N}$ and the first best solution is given in point S. Parameter values: $\Lambda=a-c=2, G=1$.

Hence, if the net willingness to pay $\Lambda=a-c$ is not too low (which implies that we are not too close to monopoly), the entrepreneur will undertake a project with higher risk than that chosen by the incumbent, and the two firms' success probabilities are strategic complements. In addition, the entrepreneur chooses too little risk from society's point of view; $p_{e}^{S}<p_{e}^{*}$. That is, the central results in Propositions 2 and 3, which were derived for the benchmark model where an innovation consists of a fixed cost reduction, also hold in this model. In addition, we can show that with homogeneous goods, the business stealing effect is positive and the result regarding the entrepreneur's project choice in Corollary 4 holds; $p_{e}^{S}<p_{e}^{*}$. An illustration is given in Figure A.2. Consequently, the main mechanisms in the model with fixed cost innovation remain valid when innovations lead to variable cost reductions in a linear Cournot model.

\section{A.3. Robustness of Entrepreneurial Hurdle Effect}

\section{A.3.1. Commercialization through sale}

Hitherto, we have assumed that the entrepreneur can only commercialize her invention through entry into the product market. However, an alternative is to sell the invention to the incumbent. If the entrepreneur faces a transaction cost associated with a sale, then the entrepreneurial commercialization hurdle effect remains. We can show that in response to an increase in the transaction cost, the entrepreneur chooses an $R \& D$ project with a higher probability of success and a lower payoff. Suppose now that if the entrepreneur's research project succeeds, the invention can only be implemented if it is sold to the incumbent firm. In this scenario, the commercialization cost takes the form of a fixed transaction cost $T \geq 0$ that the entrepreneur has to pay in case of sale. If both firms are successful, it is assumed that the incumbent always chooses to implement its own invention and, consequently, the entrepreneur's profit is zero. Hence, the entrepreneur can earn a positive profit if her selected research project is the only one that succeeds, but not otherwise. The firms are assumed to share the surplus created by the 
invention according to the Nash Bargaining solution, where the incumbent and the entrepreneur have bargaining strengths $\theta$ and $1-\theta$, respectively, $\theta \in(0,1)$. The incumbent's status-quo profit, $\bar{\pi}$, is its outside option in the bargaining. To make the problem interesting, we assume that the profit net of transaction costs is higher than the status-quo profit: $\pi\left(p_{n}\right)-T>\bar{\pi}, n \in\{i, e\}$. The entrepreneur's outside option is zero.

The entrepreneur's expected payoff when playing this game is given by:

$$
\mathrm{E}\left[\Pi_{e}\right]=p_{e}\left(1-p_{i}\right)(1-\theta)\left(\pi\left(p_{e}\right)-T-\bar{\pi}\right)-R_{S}
$$

If the entrepreneur succeeds and the incumbent fails, the incumbent will acquire the entrepreneur's invention and obtain the profit $\pi\left(p_{e}\right)$ from selling it on the market. The entrepreneur gets a share $(1-\theta)$ of the surplus created by the invention net of transaction costs and the incumbent's outside option, which is $\pi\left(p_{e}\right)-T-\bar{\pi}$. The entrepreneur pays a fixed R\&D cost $R_{S}$ in order to start a project. Let us define a function $R_{S}^{*} \equiv f\left(p_{i}, p_{e}, \pi\left(p_{e}\right), T, \bar{\pi}\right)$, where the subscript $S$ denotes sale, such that for $R_{S}=R_{S}^{*}, \mathrm{E}\left[\Pi_{e}\right]=0$. Then, two different regimes might arise in equilibrium. If $R_{S} \geq R_{S}^{*}$, the entrepreneur chooses not to perform any R\&D. If instead $R_{S}<R_{S}^{*}$, then it is optimal for the entrepreneur to choose an equilibrium value for $p_{e}, p_{e}^{*}$, implicitly defined by the following first-order condition:

$$
\frac{\partial \mathrm{E}\left[\Pi_{e}\right]}{\partial p_{e}}=\pi\left(p_{e}^{*}\right)-T-\bar{\pi}+p_{e}^{*} \pi^{\prime}\left(p_{e}^{*}\right)=0
$$

where the first three terms capture the direct effect on the expected surplus, $\pi\left(p_{e}\right)-T-\bar{\pi}$, of choosing a project with a different probability of success. The fourth term captures the indirect effect on the expected surplus of choosing a project with a different payoff. Differentiating the entrepreneur's first-order condition in $p_{e}$ and $T$, it may be concluded that:

$$
\frac{d p_{e}^{*}}{d T}=\frac{1}{2 \pi^{\prime}\left(p_{e}^{*}\right)+p_{e}^{*} \pi^{\prime \prime}\left(p_{e}^{*}\right)}<0
$$

where $2 \pi^{\prime}\left(p_{e}^{*}\right)+p_{e}^{*} \pi^{\prime \prime}\left(p_{e}^{*}\right)<0$ as a result of Assumption A1. If $T$ increases, the entrepreneur will reduce its equilibrium success probability $p_{e}^{*}$ since this reduces the expected transaction cost $p_{e}\left(1-p_{i}\right)(1-\theta) T$ and, at the same time, increases the payoff $\pi\left(p_{e}\right)$ of its research project if it succeeds. Consequently, our result that the entrepreneur chooses an R\&D project with a lower probability of success and higher payoff if the commercialization cost increases continues to hold if the entrepreneur commercializes the invention through sale instead of entry.

\section{A.3.2. The entrepreneur always enters if it succeeds}

In the baseline model, it is assumed that there is only room for the entrepreneur in the market in case the incumbent's research project has failed. Now, we examine the case when the entrepreneur always enters the market if it succeeds. The entrepreneur's expected payoff is then given by:

$$
\mathrm{E}\left[\Pi_{e}\right]=p_{e}\left(1-p_{i}\right)\left[\pi_{e}^{D}\left(p_{e}\right)-F\right]+p_{e} p_{i}\left[\pi_{e}^{D}\left(p_{e}, p_{i}\right)-F\right]-R_{E}
$$


where the corresponding first-order condition is given by:

$$
\pi_{e}^{D}\left(p_{e}^{*}\right)-F+p_{e}^{*} \pi_{e}^{D \prime}\left(p_{e}^{*}\right)+p_{i}\left\{\pi_{e}^{D}\left(p_{e}, p_{i}\right)-\pi_{e}^{D}\left(p_{e}\right)+p_{e}\left[\pi_{e, p_{e}}^{D \prime}\left(p_{e}^{*}, p_{i}\right)-\pi_{e}^{D \prime}\left(p_{e}^{*}\right)\right]\right\}=0 .
$$

From (A.19) it follows directly that $\frac{d p_{e}^{*}}{d F}<0$. Note also that:

$$
\lim _{F \rightarrow \pi_{e}^{D}\left(p_{e}, p_{i}\right)} \mathrm{E}\left[\Pi_{e}\right]=p_{e}\left(1-p_{i}\right)\left[\pi_{e}^{D}\left(p_{e}\right)-F\right]-R .
$$

So with $F$ approaching $\pi_{e}^{D}\left(p_{e}, p_{i}\right)$ the previous analysis applies. The incumbent's expected payoff is given by:

$$
\begin{aligned}
\mathrm{E}\left[\Pi_{i}\right]= & p_{i}\left(1-p_{e}\right) \pi\left(p_{i}\right)+p_{e}\left(1-p_{i}\right) \pi_{i}^{D}\left(p_{e}\right) \\
& +p_{i} p_{e} \pi_{i}^{D}\left(p_{i}, p_{e}\right)+\left(1-p_{i}\right)\left(1-p_{e}\right) \bar{\pi}
\end{aligned}
$$

with the first-order condition

$$
\left(1-p_{e}\right)\left[\pi\left(p_{i}^{*}\right)+p_{i}^{*} \pi^{\prime}\left(p_{i}^{*}\right)-\bar{\pi}\right]+p_{e}\left[\pi_{i}^{D}\left(p_{i}, p_{e}\right)+p_{i} \pi_{i, p_{i}}^{D \prime}\left(p_{i}^{*}, p_{e}\right)-\pi_{i}^{D}\left(p_{e}\right)\right]=0 .
$$

Note that since $\frac{d p_{e}^{*}}{d F}<0$ there must exist an $F$ such that $\lim _{F \rightarrow \pi_{e}^{D}\left(p_{e}, p_{i}\right)} p_{e}^{*}(F)=0$. But then (A.21) becomes:

$$
\pi\left(p_{i}^{*}\right)+p_{i}^{*} \pi^{\prime}\left(p_{i}^{*}\right)-\bar{\pi}=0
$$

Thus, when the entry costs are sufficiently high, the entrepreneur will choose more risky projects (higher quality) than the incumbent.

\section{A.3.3. Adding an entrepreneur}

Let us now examine the case with one incumbent and two entrepreneurs, where the entrepreneurs both face an entry cost $F$ if they enter the market. Let us retain the assumption that if both entrepreneurs are successful with their $R \& D$ projects while the incumbent fails, the triopoly expected profits an entrant would obtain are not sufficient to compensate for the fixed cost $F$. Further assume that entrepreneurs cannot enter if the incumbent is successful and that there is a lottery with equal probability of entry if both entrepreneurs succeed when the incumbent fails.

Then, the expected profit for an entrepreneur (for entrepreneur $1, e_{1}$, say) is:

$$
\mathrm{E}\left[\Pi_{e_{1}}\right]=\left(1-\frac{1}{2} p_{e_{2}}\right)\left(1-p_{i}\right) p_{e_{1}}\left[\pi_{e}^{D}\left(p_{e_{1}}\right)-F\right] .
$$

Note that the success probability associated with the optimal project is $p_{e_{1}}^{*}=\arg \max _{p_{e_{1}}}[(1-$ $\left.\frac{1}{2} p_{e_{2}}\right)\left(1-p_{i}\right) p_{e_{1}}\left[\pi_{e}^{D}\left(p_{e_{1}}\right)-F\right]$ which is equal to $p_{e}^{*}$ where $p_{e}^{*}=\arg \max _{p_{e}}\left[\left(1-p_{i}\right) p_{e}\left[\pi_{e}^{D}\left(p_{e}\right)-F\right]\right.$. 
The incumbent's expected profit is:

$$
\begin{aligned}
\mathrm{E}\left[\Pi_{i}\right]= & p_{i}\left(1-p_{e_{1}}\right)\left(1-p_{e_{2}}\right) \pi\left(p_{i}\right)+\left(1-p_{i}\right)\left[p_{e_{1}}\left(1-p_{e_{2}}\right) \pi_{i}^{D}\left(p_{e_{1}}\right)+p_{e_{2}}\left(1-p_{e_{1}}\right) \pi_{i}^{D}\left(p_{e_{2}}\right)\right] \\
& +p_{i}\left[p_{e_{1}} p_{e_{2}}+p_{e_{1}}\left(1-p_{e_{2}}\right)+p_{e_{2}}\left(1-p_{e_{1}}\right)\right] \pi\left(p_{i}\right) \\
& +\left(1-p_{i}\right)\left(1-p_{e_{1}}\right)\left(1-p_{e_{2}}\right) \bar{\pi} .
\end{aligned}
$$

For a sufficiently high $F$, both entrepreneurs will choose a project with very high quality, i.e. $\lim _{F \rightarrow \pi_{e}^{D}\left(p_{e_{v}}\right)} p_{e_{v}}^{*}(F)=0, v \in\{1,2\}$. The incumbent's project is then given as $p_{i}^{*}=$ $\arg \max _{p_{i}} E\left[\Pi_{i}\right]=\arg \max _{p_{i}}\left[p_{i} \pi\left(p_{i}\right)+\left(1-p_{i}\right) \bar{\pi}\right]$, where we once more have $p_{i}^{*}>0$. Thus $p_{i}^{*}>p_{e_{v}}$, and it follows that for a sufficiently large $F$, the entrepreneurs choose more breakthrough inventions than the incumbent.

\section{A.3.4. Adding an incumbent}

Let us now add another incumbent, so that the market consists of two incumbents and one entrepreneur. The entrepreneur faces an entry $\operatorname{cost} F$ if it enters the market. Let $p_{i_{j}}$ denote the success probability corresponding to the research project selected by the incumbent $j, j=1,2$. In line with the previous analysis, we will assume that the entrepreneur only enters the market in case it is successful with the chosen research project while both incumbents fail. When this is the case, $\pi_{e}^{T}\left(p_{e}\right)$ denotes the entrepreneur's triopoly profit. As before, this (triopoly) profit is independent of the incumbents' success probabilities since oligopoly competition only occurs when incumbents' R\&D projects have failed. The entrepreneur's expected profit is then given by

$$
\mathrm{E}\left[\Pi_{e}\right]=p_{e}\left(1-p_{i_{1}}\right)\left(1-p_{i_{2}}\right)\left[\pi_{e}^{T}\left(p_{e}\right)-F\right]-R_{F} .
$$

So, if $R_{F}$ is sufficiently small that the entrepreneur chooses to invest, it will choose an equilibrium value for $p_{e}, p_{e}^{*}$, implicitly defined by the following first-order condition:

$$
\frac{\partial \mathrm{E}\left[\Pi_{e}\right]}{\partial p_{e}}=\pi_{e}^{T}\left(p_{e}^{*}\right)-F+p_{e}^{*} \pi_{e}^{T \prime}\left(p_{e}^{*}\right)=0 .
$$

Now, differentiating the previous first-order condition in $p_{e}$ and $F$, it may be concluded that:

$$
\frac{d p_{e}^{*}}{d F}=\frac{1}{2 \pi_{e}^{T \prime}\left(p_{e}^{*}\right)+p_{e}^{*} \pi_{e}^{T \prime \prime}\left(p_{e}^{*}\right)}
$$

which turns out to be negative since $2 \pi_{e}^{T \prime}\left(p_{e}^{*}\right)+p_{e}^{*} \pi_{e}^{T \prime \prime}\left(p_{e}^{*}\right)<0$ (Assumption 2 holds for $\pi_{e}^{T}\left(p_{e}^{*}\right)$ ). Hence, the commercialization hurdle effect remains when we extend the model to encompass more than one incumbent. Moreover, it remains true that high fixed costs $F$ will force the entrepreneur to choose a very risky strategy, $\lim _{F \rightarrow \pi_{e}^{T}\left(p_{e}\right)} p_{e}^{*}(F)=0$. 